\title{
The role of contextual versus discrete drug-associated cues in promoting the induction of psychomotor sensitization to intravenous amphetamine
}

\author{
Hans S. Crombag ${ }^{1}$, Aldo Badiani ${ }^{2}$, Stephen Maren, Terry E. Robinson * \\ Biopsychology Program, Department of Psychology, The University of Michigan, East Hall, 525 East University, Ann Arbor, \\ MI 48109-1109, USA
}

Received 10 March 2000; received in revised form 15 May 2000; accepted 15 May 2000

\begin{abstract}
The environmental context in which psychostimulant drugs are administered can have a large effect on both their acute psychomotor activating effects and their ability to induce the psychomotor sensitization associated with repeated drug administration. For example, the acute effects of amphetamine and the development of psychomotor sensitization to amphetamine and cocaine are enhanced when they are administered in a distinct and relatively novel test environment, relative to when they are given in the home cage, in the absence of any environmental stimuli predictive of drug administration. The experiments reported here were designed to further examine this phenomenon and to test the hypothesis that the ability of a distinct context to promote robust psychomotor sensitization is due to its ability to reliably signal (cue) drug administration. Specifically, we compared the ability of contextual cues (a distinct test environment) and discrete cues (light, tone and/or odor), which both reliably predict drug administration, to promote the induction of sensitization. The psychomotor stimulant effects (rotational behavior) of repeated intravenous infusions of $0.5 \mathrm{mg} / \mathrm{kg}$ amphetamine were assessed in rats for whom drug treatments were signaled either: (1) by placement into a distinct test environment; (2) by presentation of discrete cues; or (3) rats for whom drug treatments were given in the home environment in the absence of any environmental cues. Amphetamine produced robust sensitization when given in association with placement into a distinct test environment. The same treatment failed to produce sensitization when the drug was given unsignaled in the animal's home cage. Most importantly, signaling drug administration by presenting discrete cues was not sufficient to promote the robust sensitization seen when treatments were given in a distinct test environment. These results confirm that the induction of psychomotor sensitization can be powerfully modulated by environmental context and further establish that, although contextual stimuli associated with a distinct test environment promote robust sensitization, discrete cues that merely predict drug administration do not have this property. Possible reasons for the difference in the ability of contextual versus discrete environmental cues to promote sensitization are discussed. (c) 2000 Elsevier Science B.V. All rights reserved.
\end{abstract}

Keywords: Amphetamine; 6-Hydroxydopamine; Rotational behavior; Sensitization; Context; Associative learning; Stress; Predictability; Rat

\footnotetext{
* Corresponding author. Tel.: +1-734-7631304; fax: +1-7347637480

E-mail address: ter@umich.edu (T.E. Robinson).

${ }^{1}$ Present address: Intramural Research Program, Behavioral Neuroscience Branch, The National Institute on Drug Abuse, 5500 Nathan Shock Drive, Baltimore, MD 21224, USA.

${ }^{2}$ Present address: Institute of Medical Pharmacology, University of Rome 'La Sapienza', 00185 Rome, Italy.
}

\section{Introduction}

The effects of drugs of abuse, such as amphetamine and cocaine, change when they are given repeatedly. Some of their effects decrease, i.e. show tolerance, whereas other effects increase, i.e. show sensitization (for reviews see Refs. [76,84,87]). The psychomotor stimulant effects of drugs typically sensitize with repeated drug treatment. For example, repeated intermittent treatment with amphetamine or cocaine produces 
long-lasting sensitization of locomotor activity and stereotyped behaviors in neurologically intact rats $[54,82]$ and rotational behavior in animals with a unilateral lesion of the mesostriatal dopamine pathway $[31,73]$. Also, the rewarding properties of amphetamine and cocaine, that is, their ability to promote self-administration or a conditioned place preference, show sensitization $[47,53,65]$. These findings have led to the hypothesis that drug-induced neuroadaptations underlying sensitization may play an important role in the induction and maintenance of the compulsive patterns of drug-seeking behavior that characterize addiction [75,77].

In part because of its potential role in addiction, and in part because it is a compelling example of experience-dependent neuroplasticity, there has been considerable interest in identifying variables that promote (or retard) the induction of sensitization. Indeed, it is well established that the magnitude of psychomotor sensitization varies considerably depending on a number of factors, including dose of the drug, treatment regimen and the genotype of the test subject $[74,76,87]$. Furthermore, there is evidence that the context in which drugs are administered (i.e. 'set and setting') can powerfully modulate psychomotor sensitization [78]. Under some experimental conditions, for example, the expression of sensitization can come under strong conditioned stimulus control $[1,43,58,63,91,94]$. In this case repeated exposure to psychostimulant drugs may induce 'neural sensitization', i.e. produce the relevant adaptations in the nervous system, but the context in which a drug challenge is given determines whether neural sensitization is expressed behaviorally $[63,78,88]$. This phenomenon is known as context- or environment-specific sensitization. Less is known, however, about the role of environmental context in modulating the ability of drugs to produce sensitization-related neuroadaptations in the first place [78]. In this case the issue is whether environmental context can modulate the magnitude or rate (the 'induction') of behavioral sensitization and not whether behavioral sensitization is expressed or not (as with context-specific sensitization).

In a series of studies, we have reported that the susceptibility to psychomotor sensitization is enhanced when amphetamine or cocaine are administered in a distinct and relatively novel test environment, compared to when the same drug treatment is given in the animal's home cage [5-7]. The effect of environmental context is especially large when drug treatments are given intravenously via a remote-controlled infusion pump that eliminates exposure of the 'home' animals to drug-related stimuli (e.g. the experimenter, handling, a needle jab) [18,19,26,36]. Although these studies demonstrate that environmental context can modulate the induction of sensitization, they have not identified the critical feature(s) of the environment that promote (or retard) sensitization. In these experiments the 'home' and 'novel' environments were physically identical, excluding the possibility that the effect is due to physical differences between the two environments. Another possibility is that a distinct environment facilitates the induction of sensitization by promoting associative learning processes. It has been argued, for example, that behavioral sensitization is due to treatment-related stimuli acquiring conditioned stimulus (CS), properties and thus, the ability to elicit a conditioned response (CR) $[43,63,69,91]$. By this view, sensitization occurs because with repeated drug treatments the progressively increasing $\mathrm{CR}$ adds to the unchanging unconditioned psychomotor drug effects. To the extent that associative learning contributes to the induction of sensitization, one would expect greater psychomotor sensitization when drug injections are reliably signaled by environmental cues (e.g. the treatment context), than when there are no cues that predict drug administration. The major purpose of the experiments reported here, therefore, was to further explore this 'associativelearning' hypothesis.

In our previous experiments there were many contextual cues associated with drug administration, including tactile stimuli (transport and handling, the cage floor), visual stimuli (the appearance of the testing room and the test cage), auditory stimuli (white noise), olfactory stimuli (the smell of bedding) and also the interoceptive stimuli produced by the drug itself. Thus, by its very nature a distinct test environment provides a complex, multimodal contextual stimulus. The purpose of the present experiments was to determine whether discrete stimuli that predict drug administration would be similarly effective at promoting robust sensitization. This distinction between contextual cues and discrete cues may be particularly relevant in light of recent conceptual developments in the field of learning theory regarding the role of context in learning [12]. For example, there is increasing evidence to suggest that conditioning to contextual cues versus discrete cues is mediated by different, albeit overlapping, neural systems [46,55,64].

Unfortunately, there is little published information on the ability of discrete cues paired with experimenteradministered drug injections to acquire conditioned stimulus properties (for examples see Refs. $[33,61,66,93])$, let alone to enhance sensitization. In the present study, we addressed this issue by comparing the rate and extent of psychomotor sensitization in three groups of rats: (1) a group that received repeated i.v. infusions of amphetamine following transport and placement into a distinct and relatively novel test environment (NOVEL); (2) a group that received repeated i.v. infusions in their home cage during and following presentation of discrete auditory, visual and/or olfactory stimuli $\left(\mathrm{HOME}^{+}\right)$; and (3) a group that received repeated i.v. infusions of amphetamine in their home 
cage in the absence of any environmental stimuli $\left(\mathrm{HOME}^{-}\right)$. In Experiments 1-3, we used different combinations of visual, auditory and olfactory stimuli to signal drug administration in the home cages. In Experiment 4, we used a highly salient cue (a tone that had previously been paired with footshock). To ensure that the rats were alert during cue presentation in Experiments 2 and 4, the test cages were vibrated (by remote control) prior to cue presentation and drug administration. In all experiments, we used a remote-controlled intravenous drug delivery procedure $[22,66]$, which provides two major advantages over more traditional routes of drug administration, such as intraperitoneal injections. First, it allows maximal control over environmental stimuli associated with drug administration. Second, it allows drug administration without the potentially stressful consequences of handling and a needle jab.

We report that repeated intravenous injections of 0.5 $\mathrm{mg} / \mathrm{kg}$ amphetamine failed to produce sensitization when given in the absence of drug predictive cues. In contrast, amphetamine produced robust sensitization when drug administration was signaled by placement into a distinct and relatively novel test environment. Finally, amphetamine produced only very modest sensitization when drug treatments were signaled by discrete cues in the home cage. Taken together, these findings indicate that discrete cues are not sufficient to produce the robust sensitization that occurs when amphetamine is given in association with placement into a distinct test context. Possible reasons for this difference between contextual and discrete stimuli are discussed.

\section{Materials and methods}

\subsection{Subjects}

Male Sprague-Dawley rats, purchased from Harlan Sprague Dawley (Indianapolis, IN) were used in all experiments. The rats weighed between 200 and $225 \mathrm{~g}$ on arrival and were housed individually in stainlesssteel wire hanging cages in a climate controlled animal colony, maintained on a 14:10 cycle (light:dark, lights on at 08:00). Food and water were available ad libitum for the duration of the experiment.

\subsection{Behavioral measure}

The psychomotor stimulant effects of amphetamine were quantified by measuring amphetamine-induced rotational behavior in rats with a unilateral lesion of the nigrostriatal dopamine pathway [92]. The quantification of rotational behavior provides a number of methodological advantages over more commonly used measures of psychomotor activation, such as locomotor crossover activity or stereotyped behaviors in neurologically intact rats $[5,6,26]$. Most importantly, in rats with a unilateral lesion, a progressive increase in drug effect is characterized by a progressive increase in rotational behavior over a wide range of doses of amphetamine $[25,92]$. In contrast, in neurologically intact rats, a progressive increase in drug effect produces a progressive increase in locomotor activity within only a narrow range of doses of amphetamine [25,83]. As a consequence, sensitization-dependent changes in psychomotor stimulant effects are more readily detected using rotational behavior in rats with a unilateral lesion $[25,73]$. In addition, measuring rotational behavior is particularly useful for studies investigating the effects of the environment on psychomotor stimulant sensitization because the unconditioned rotational response produced by exposure to a novel test environment alone is small. In contrast, in neurologically intact rats, exposure to a novel test environment can produce a very large increase in locomotor crossover activity that may conceal sensitization-dependent changes in psychomotor activation $[5,6]$.

\subsection{Surgical procedures}

Following a minimum of 7 days of acclimatization to the animal colony, the rats were pretreated with atropine methyl nitrate $(5 \mathrm{mg} / \mathrm{kg}$, i.p.) and then anesthetized with sodium pentobarbital $(52 \mathrm{mg} / \mathrm{kg}$, i.p., The Butler Co., Columbus, OH), and supplemented with methoxyflurane (Schering-Plough Animal Health Corp., NJ) when necessary. Using standard stereotaxic procedures, a 21-gauge stainless steel guide cannula was positioned over the medial forebrain bundle. The following coordinates were measured from bregma: anterior/posterior $-3.0 \mathrm{~mm}$; medial/lateral $\pm 1.8 \mathrm{~mm}$, and measured from skull surface: dorsal/ventral $-1.0 \mathrm{~mm}$. In half of the rats, the cannula was placed over the left hemisphere and in the other half over the right hemisphere. In addition to the guide cannula, a length of 15-gauge stainless steel tubing and a length of polyethylene tubing, both bent at a $90^{\circ}$ angle were positioned on the skull surface. These served as an anchor for tethering and as a support for the intravenous catheter, respectively. The entire assembly was affixed to the skull surface using jeweler screws and dental cement. The guide cannula was capped with a stainless steel stylet.

Following a 3-day recovery period, all rats received a unilateral 6-hydroxydopamine (6-OHDA) lesion of the nigrostriatal dopamine pathway using the following procedures. 6-OHDA $\mathrm{HBr}$ was freshly dissolved (2 $\mathrm{mg} / \mathrm{ml})$ in a cold $0.9 \% \mathrm{NaCl}$ and ascorbic acid $(0.1$ $\mathrm{mg} / \mathrm{ml}$ ) solution. Rats were pretreated with desipramine hydrochloride $(15 \mathrm{mg} / \mathrm{kg}$, i.p.) to protect noradrenergic terminals [16]. Between 20 and 30 min later, a 29 gauge 
infusion cannula was lowered, through the guide cannula, into the medial forebrain bundle $(8.3 \mathrm{~mm}$ ventral from skull surface) and $4 \mu$ of 6-OHDA was infused over an 8 -min period $(0.5 \mu \mathrm{l} / \mathrm{min})$. The infusion cannula was left in place an additional $2 \mathrm{~min}$ to minimize diffusion upward the cannula tract.

Ten days after the 6-OHDA lesion, the rats were screened for the development of dopamine receptor supersensitivity (denervation supersensitivity) by administering apomorphine $(0.05 \mathrm{mg} / \mathrm{kg}$, s.c. into the nape of the neck) and measuring contraversive rotational behavior. This dose of apomorphine produces vigorous circling behavior only when $>90 \%$ of the dopamine input to the striatum has been lesioned unilaterally $[40,56]$. Following the apomorphine injection $(10 \mathrm{~min})$ the rats were observed and rats that made fewer than five full rotations in a 1-min period were later re-lesioned and re-screened using identical procedures. Rats that did not then meet the screening criterion were excluded from the study.

Intravenous catheters were implanted using procedures described previously [26,29]. Briefly, catheters were constructed from silastic tubing $(0.30 \mathrm{~mm}$ ID, 0.64 $\mathrm{mm}$ OD) and two sizes of polyethylene tubing (0.38 $\mathrm{mm}$ ID, $1.09 \mathrm{~mm}$ OD and $0.28 \mathrm{~mm}$ ID, $0.61 \mathrm{~mm}$ OD) as described by Weeks [96]. Rats were anesthetized with a combination of ethyl ether (to induce anesthesia) and methoxyflurane (to maintain anesthesia) and the catheter was implanted such that the silicone end was inserted into the right external jugular vein and the polyethylene end exited dorsally through the nape of the neck. The catheter was then secured by inserting it through the L-shaped length of polyethylene tubing that had been affixed to the skull. Following catheter implantation, the rats were allowed to recover for at least 4 days before testing began. During this period, the catheters were flushed daily with $0.1 \mathrm{ml}$ of heparin solution $(30 \mathrm{U} / \mathrm{ml}$, in $0.9 \%$ sterile saline buffered at $\mathrm{pH}=7.4)$ and $0.1 \mathrm{ml}$ of gentamicin $(50 \mathrm{mg} / \mathrm{ml})$ to prevent occlusions and to circumvent microbial buildup in the catheter. Throughout the experiments the catheters were flushed once daily with $0.1 \mathrm{ml}$ of heparin. All drugs were purchased from Sigma (St. Louis, MI) unless noted otherwise.

At the end of each experiment, the catheters were tested for patency by injecting intravenously $0.1 \mathrm{ml}$ of the short-acting barbiturate Pentothal ${ }^{\circledR}$ (Thiopental sodium, $20 \mathrm{mg} / \mathrm{ml}$ in sterile water). Rats that did not become ataxic within $5 \mathrm{~s}$ were excluded from the analyses.

\subsection{Apparatus}

The test cages consisted of plastic round buckets with a flat-bottomed floor (diameter: $25 \mathrm{~cm}$, height: $36 \mathrm{~cm}$ ). The floor of each cage was covered with granulated corn-cob. Each rat was tethered via a length of lightweight stainless steel cable to a home-made liquid swivel [20], which was mounted on a counterbalanced arm (Applied Concepts, Ann Arbor, MI). This allowed the animal to move freely in the test cage. Syringe pumps, programmed to infuse at a flow-rate of either $10 \mu \mathrm{l} / \mathrm{min}$ (Experiment 1) or $20 \mu \mathrm{l} / \mathrm{min}$ (Experiments 2-4) were located inside the testing room, but the control equipment was located in an adjacent room. Each test cage was equipped with a photocell based automated rotometer (Applied Concepts, Ann Arbor, $\mathrm{MI}$ ), which recorded full turns (four consecutive $90^{\circ}$ turns) using an XT-based personal computer [59].

In Experiments 1 and 2, the HOME groups lived and received drug treatments in cages equipped with a $5 \mathrm{~W}$ circular white cue light (diameter: $1.5 \mathrm{~cm}$ ) located $\approx 9$ $\mathrm{cm}$ above the cage floor. These cue lights were normally off, and provided the visual component of the drug predictive cue (Experiments 1 and 2). A centrally located speaker provided a constant white noise signal $(60 \mathrm{~dB})$ to mask extraneous sounds. In Experiments $1-3$, this speaker was also the source of the auditory component of the drug predictive cue, which consisted of a high pitched tone $(85 \mathrm{~dB})$. In Experiment 4, the auditory cue (a 1-min burst of white noise) was presented through a small speaker mounted to the outside wall of the test cage. The control modules for the cue lights and the sound generators were located outside the testing room. In Experiments 2 and 4, small remotecontrolled vibrators were attached to the outside wall of each test cage and provided a vibratory cue. A more detailed description of the different stimuli used in each experiment is provided below.

\subsection{Data analyses and statistics}

The acute rotational response to amphetamine (first test session) was analyzed for differences between groups using a one-way analysis of variance (ANOVA), followed by planned Fisher's protected least significant difference tests (PLSD). The development of psychomotor sensitization was evaluated using two indices. The first index was provided by the change in rotational behavior with successive injections of amphetamine (i.e. a within-subjects measure of sensitization). As discussed earlier, in rats with a unilateral lesion of the nigrostriatal dopamine pathway, an increase in drug effect is characterized by a linear increase in rotational behavior over a wide range of doses and therefore, changes in drug effectiveness can be assessed by performing linear regression analyses [5-7]. Sensitization is indicated by a positive slope (slope coefficient $>0$ ), and the greater the slope coefficient the greater the rate of sensitization. Slope coefficient data for each group were analyzed using one-sample $t$-tests and group differences were determined using Student's $t$-tests. The second index of 
sensitization was provided by comparing the behavioral response to a challenge injection of amphetamine in amphetamine-pretreated versus saline-pretreated rats (i.e. a between-subjects measure of sensitization). With this method sensitization is indicated by a significantly greater response in amphetamine-pretreated than in saline-pretreated rats. Group differences in the magnitude of sensitization were analyzed using two-way ANOVAs (pretreatment drug-by-treatment condition), followed by Fisher's PLSD tests. Similarly, the response to a challenge injection of saline (to test for the development of a conditioned response) was analyzed using two-way ANOVAs, followed by Fisher's PLSD tests. Finally, we also examined whether the rate of sensitization was predicted either by the acute response (first test session) to amphetamine, or, by the ability of treatment related stimuli to acquire conditioned stimulus properties. The hypothesis that the acute response to amphetamine predicts the rate of sensitization was tested with linear correlation analyses of rotational scores on the first test session (acute response) versus the slope coefficients (sensitization). The second hypothesis was tested using a linear correlation analyses of rotational scores on the saline challenge test (conditioned response) versus the slope coefficients (sensitization). These analyses were conducted on the pooled data from Experiments 1-3 and are presented in Section 6.2.

Detailed statistics are reported in the figure captions in order to make the results sections easier to read. However, no statements are made regarding group differences in the results sections that are not supported by significant statistical tests $(P<0.05)$.

\section{Experiment 1}

We have reported previously that the susceptibility to sensitization is enhanced when amphetamine treatments are given in distinct test environment, relative to when the same treatments are given in the absence of treatment related stimuli, in the rat's home cage $[19,26,36]$. It is possible that when given in a distinct context amphetamine produces more robust behavioral sensitization, because the context acts as a drug predictive cue, thereby promoting associative learning processes. The purpose of Experiment 1 was to determine whether signaling drug administration using discrete cues would be as effective as a distinct context in facilitating psychomotor sensitization.

\subsection{Methods}

\subsubsection{Groups}

All groups received drug treatments in physically identical test cages, because the physical characteristics of the test environment can have a large effect on both the quantity and quality of the behavioral response to drugs $[15,32,79,89]$ and on the induction of sensitization [44].

There were six independent groups: $\operatorname{NOVEL}^{(a)}(N=$ 14), NOVEL ${ }^{(\mathrm{s})} \quad(N=13), \quad \mathrm{HOME}^{+(\mathrm{a})} \quad(N=16)$,

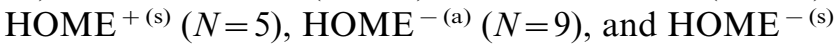
$(N=5) . N$ refers to the number of animals per group after verification of catheter patency.

3.1.1.1. NOVEL ${ }^{(s)}$ and NOVEL ${ }^{(a)}$ groups. These animals were housed in the main animal colony in wirehanging cages (see below) throughout the experiment. Each test day, these rats were transported to a different room and placed into the distinct test environment described above, where within $10-120 \mathrm{~s}$ they received an intravenous injection of either saline $\left(\mathrm{NOVEL}^{(\mathrm{s})}\right)$ or amphetamine (NOVEL ${ }^{(a)}$ ). Thus, for these rats drug administration was signaled by the test context.

3.1.1.2. $\mathrm{HOME}^{+(s)}$ and $\mathrm{HOME}^{+(a)}$ groups. These animals lived in the test cages (see below), where they received intravenous injections of saline $\left(\mathrm{HOME}^{+(\mathrm{s})}\right)$ or amphetamine $\left(\mathrm{HOME}^{+}{ }^{(\mathrm{a})}\right)$ using remotely controlled syringe pumps. In these groups drug administration was paired with the presentation of a discrete compound stimulus (see below).

3.1.1.3. HOME ${ }^{-(s)}$ and HOME-(a) groups. These animals also lived in the test cages, where they received intravenous injections of saline $\left(\mathrm{HOME}^{-(\mathrm{s})}\right)$ or amphetamine $\left(\mathrm{HOME}^{-(\mathrm{a})}\right)$ using remotely controlled syringe pumps. In these groups, however, stimulus presentation and drug administration were always unpaired (except on the amphetamine and saline challenge tests, see Section 3.1.2). Thus, for these rats drug administration was not signaled by any environmental stimuli.

\subsubsection{Procedures}

3.1.2.1. Habituation. Immediately following catheter implantation rats assigned to the $\mathrm{HOME}^{-}$and $\mathrm{HOME}^{+}$ groups were housed in test cages located in a climatecontrolled and sound-attenuated testing room and they remained there for the duration of the experiment. White noise was on at all times except during cue presentation (see Section 3.1.2.2). Two days following housing each rat was tethered, via a light-weight flexible cable, to the liquid swivel mounted on a counter-balanced arm. The rats remained tethered for the remainder of the experiment, except for short periods when they were weighed. On the third day of the habituation phase, these rats received the first of a series of three unsignaled intravenous injections of heparin. This was done in order to habituate them to the injection ritual. 
The following procedures were used. Each morning at $\approx 8: 00 \mathrm{~h}$ the experimenter entered the testing room and filled the infusion line, consisting of a length of PE20 tubing, with heparin solution $(30 \mathrm{U} / \mathrm{ml})$. Next, the catheters were manually flushed with $0.1 \mathrm{ml}$ heparin (to clear any obstructions) and connected to the liquid swivel with PE20 tubing. A second length of PE20 tubing connected the swivel to a 1.0-ml syringe mounted on a syringe pump. When all the infusion lines had been connected to the catheters the animals were left undisturbed. Later during the day, the $\mathrm{HOME}^{+}$and $\mathrm{HOME}^{-}$groups received an unsignaled injection of $60 \mu \mathrm{l}$ of heparin at a flow rate of $10 \mu \mathrm{l} / \mathrm{min}$ by remotely activating the syringe pumps. At $\approx 18: 00 \mathrm{~h}$ the experimenter entered the testing room and the infusion lines were disconnected, the catheters were sealed and the cages were serviced when necessary. During the habituation phase the rats in the NOVEL groups remained undisturbed in the main animal colony except that their catheters were flushed manually once each day with $0.1 \mathrm{ml}$ of heparin solution. These animals were housed in square stainless steel wire hanging cages $(18 \times 25 \mathrm{~cm})$ and the waste trays below the cages were covered with pine-wood shavings.

3.1.2.2. Intermittent drug treatment. During the treatment phase, all groups received nine consecutive daily intravenous infusions of either $0.5 \mathrm{mg} / \mathrm{kg}$ D-amphetamine $\left(\mathrm{NOVEL}^{(\mathrm{a})}, \mathrm{HOME}^{+(\mathrm{a})}\right.$ and $\mathrm{HOME}^{-(\mathrm{a})}$ ) or saline $\left(\mathrm{NOVEL}^{(\mathrm{s})}, \mathrm{HOME}^{+(\mathrm{s})}\right.$ and $\mathrm{HOME}^{-(\mathrm{s})}$ ), on a schedule that consisted of one injection per day. This dose of amphetamine has previously been shown to produce a large acute response and robust psychomotor sensitization when given in a distinct test environment $[19,78]$. The treatment phase was interrupted on day 8 to test for the development of a conditioned response (see Section 3.1.2.3). For the $\mathrm{HOME}^{-}$and $\mathrm{HOME}^{+}$ groups, the injection procedures were identical to those used during the habituation phase of the experiment, except that this time the infusion lines were loaded with $15 \mu 1$ of amphetamine or saline. The remainder of the infusion line was filled with heparin solution, which was separated from the drug solution by a small air bubble to prevent diffusion. After connecting the infusion lines to the catheters the rats were again left undisturbed until later during the day when the syringe pumps were remotely activated. Because time of day may serve as a drug predictive cue, rats were injected at different times each test day, either at 11:00, 13:00 or 15:00 h (balanced across treatment conditions). Each intravenous injection consisted of an initial $20 \mu 1$ of heparin (volume of catheter), followed by $15 \mu \mathrm{l}$ of amphetamine or saline followed by an additional $25 \mu 1$ of heparin. Thus, the total injection volume was $60 \mu$, which was delivered at a flow rate of $10 \mu \mathrm{l} / \mathrm{min}$, i.e. $6 \mathrm{~min}$ injection. Although the entire infusion lasted $6 \mathrm{~min}$, note that the $15-\mu 1$ drug (or saline) bolus was injected over $90 \mathrm{~s}$.
For rats assigned to the $\mathrm{HOME}^{+}$condition drug administration was paired with a $30-$ min presentation of a compound stimulus consisting of a flashing light and a discontinuous tone (cycling at $\approx 0.5 \mathrm{~s}$ on and 0.5 $\mathrm{s}$ off). These were presented simultaneously and preceded the drug injection by $1 \mathrm{~min}$ and remained on for $30 \mathrm{~min}$ (the white noise was turned off during this period). Thus, for this group, drug administration was always signaled by the presentation of this compound stimulus. The $\mathrm{HOME}^{-}$groups were also exposed for $30 \mathrm{~min}$ to the light/tone stimulus, but, for these animals, cue presentation and drug administration were always unpaired, i.e. sometimes the stimulus preceded drug administration by $\approx 2 \mathrm{~h}$, and sometimes the stimulus followed drug administration by $\approx 2 \mathrm{~h}$. At the end of the day the infusion lines were disconnected, the catheters were sealed and the testing room was secured until the next day.

At approximately the same time of day as when the $\mathrm{HOME}^{+}$and $\mathrm{HOME}^{-}$groups received their injections, animals in the NOVEL group were transported from their home cages in the animal colony to a test room containing cages that were physically identical to those in which the $\mathrm{HOME}^{+}$and $\mathrm{HOME}^{-}$animals lived. Their catheters were manually flushed, the infusion lines were loaded with amphetamine $\left(\mathrm{NOVEL}^{(\mathrm{a})}\right)$ or saline $\left(\mathrm{NOVEL}^{(\mathrm{s})}\right)$ and were connected to the catheters and the rats were tethered to the automated rotometers. The two groups then received their respective intravenous treatments using the same injection procedures and equipment as described above. No light/tone cue was presented, because for this group placement into the distinct test environment reliably signaled drug administration. At the end of the test session the NOVEL animals were disconnected from their tethers, their catheters were sealed and they were returned to the animal colony until the following day.

3.1.2.3. Saline challenge. As mentioned above, the treatment phase of the experiment was interrupted on day 8 to test for the development of a conditioned response by measuring rotational behavior in response to challenge injection of saline. All procedures were identical to those described above, except that all groups received an injection of saline, and, for both the $\mathrm{HOME}^{+}$ and $\mathrm{HOME}^{-}$groups, the injection was paired with the presentation of the light/tone stimulus. Because the unpaired presentation of the cue during the saline challenge could have reduced the associative strength between these stimuli and drug administration, all groups were given two additional treatment injections of amphetamine (or saline), over the next 2 days.

3.1.2.4. Withdrawal and amphetamine challenge. Following the last treatment day, drug treatment was discontinued for 6 days. Following this withdrawal period, 
during which time animals were handled as in the habituation phase, all groups (including the saline control groups) received a challenge i.v. infusion of 0.5 $\mathrm{mg} / \mathrm{kg}$ of amphetamine to test for the expression of sensitization. For both the $\mathrm{HOME}^{-}$and the $\mathrm{HOME}^{+}$ groups, drug administration was paired with stimulus presentation on the challenge test day.

During each test session rotational behavior was recorded in 5-min bins for a total of $90 \mathrm{~min}$ following drug administration. For the $\mathrm{HOME}^{-}$and $\mathrm{HOME}^{+}$ groups rotational behavior was recorded during an additional $15 \mathrm{~min}$ prior to drug administration to assess baseline rotational activity.

\subsection{Results: Experiment 1}

Fig. 1 shows the effects on rotational behavior of nine intravenous injections of $0.5 \mathrm{mg} / \mathrm{kg}$ amphetamine or saline (panel A), a challenge injection of $0.5 \mathrm{mg} / \mathrm{kg}$ amphetamine (panel C) and a challenge injection of saline (panel D) given to rats: (i) after placement into the novel test environment (NOVEL); (ii) in the home cage when drug administration was signaled by a discrete stimulus $\left(\mathrm{HOME}^{+}\right)$; or (iii) in the home cage when drug administration was unsignaled $\left(\mathrm{HOME}^{-}\right)$. For illustrative purposes Fig. 2 shows the time course of rotational behavior following the first and ninth injection of amphetamine (top panels) or saline (bottom panels) and Fig. 3 shows the time course of rotational behavior during the amphetamine (top panels) and saline challenge tests (bottom panels).
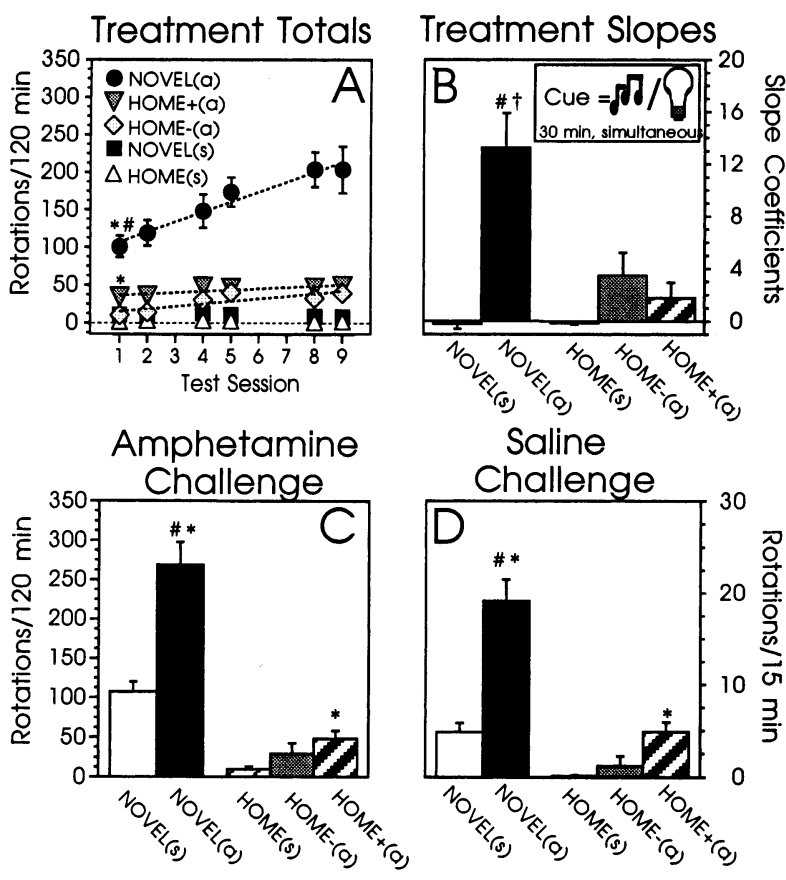

Fig. 1.
The first and subsequent injections of saline produced no behavioral response in either the $\mathrm{HOME}^{-(\mathrm{s})}$ or $\mathrm{HOME}^{+(s)}$ groups (Fig. 1A), and these two groups did not differ significantly at any time during the experiment. Therefore, the data from these groups were pooled to yield a single control group $\left(\mathrm{HOME}^{(\mathrm{s})}\right)$. Inspection of the time course data reveals that there was a small increase in rotations during the first $5 \mathrm{~min}$ of the first test session following placement into the novel test environment (Fig. 2D). However, this effect dissipated over test sessions presumably as a result of habituation to the novel test environment.

An intravenous injection of amphetamine produced an immediate increase in rotational behavior within the first 5 min after the treatment (Fig. 2). This is consistent

Fig. 1. (A) The mean ( \pm S.E.M.) number of rotations during the first, second, fourth, fifth, eighth and ninth test session for rats that received intravenous injections of saline or $0.5 \mathrm{mg} / \mathrm{kg}$ amphetamine. The injections were given in association with either placement into a distinct test environment $\left(\mathrm{NOVEL}^{(\mathrm{s})}\right.$ and NOVEL $\left.{ }^{(\mathrm{a})}\right)$, or in the home cage in association with the presentation of discrete stimuli $\left(\mathrm{HOME}^{(\mathrm{s})}\right.$ and $\mathrm{HOME}^{+(\mathrm{a})}$ ), or in the home cage, but unsignaled $\left(\mathrm{HOME}^{(\mathrm{s})}\right.$ and $\mathrm{HOME}^{-(\mathrm{a})}$ ). The first and subsequent injections of saline in all three treatment conditions produced negligible rotational behavior during any of the test sessions. A one-way ANOVA indicated that there was a significant effect of group on the first test session $(F=25.1$, $P<0.0001)$. The initial injection of amphetamine produced a significant increase in rotational behavior in the NOVEL ${ }^{(a)}$ and $\mathrm{HOME}^{+(\text {a) }}$ groups (Fisher's PLSD, $P<0.01$ ), but not in the $\mathrm{HOME}^{-}$group. Furthermore, the acute response was greater in the NOVEL ${ }^{(a)}$ than in the $\mathrm{HOME}^{+(\mathrm{a})}$ group (Fisher's PLSD, $P<0.0001$ ) and the latter group did not differ significantly from the $\mathrm{HOME}^{-}$(a) group. (B) The results of the linear regression analysis indicate that only the NOVEL $^{(a)}$ group showed an increase in rotations over test sessions, i.e. sensitization (one-sample $t$-test, mean \pm S.E.M. slope coefficient $=13.26, t=5.4, P<0.0001)$. (C) Mean ( \pm S.E.M.) number of rotations on the amphetamine challenge day for rats pretreated with amphetamine or saline in the NOVEL, $\mathrm{HOME}^{+}$or $\mathrm{HOME}^{-}$conditions. A one-way ANOVA indicated that there was a significant effect of group $(F=29.2, P<0.0001)$. Rats in the NOVEL and $\mathrm{HOME}^{+}$ groups, and pretreated with amphetamine, showed a greater response than saline-pretreated rats (Fisher's PLSD, $P<0.05$ ), indicating that these groups were sensitized. The magnitude of sensitization was greater in the NOVEL (a) group than in the $\mathrm{HOME}^{+}$(a) group, as indicated by a significant interaction effect (two-way ANOVA, effect of drug, $F=34.5, P<0.0001$; effect of condition, $F=55.4, P<0.05$; effect drug-by-condition, $F=9.6, P<0.01$ ). Furthermore, the response of the $\mathrm{HOME}^{+ \text {(a) }}$ and $\mathrm{HOME}^{- \text {(a) }}$ groups did not differ. (D) Mean $( \pm$ S.E.M.) number of rotations during the first $15 \mathrm{~min}$ of the saline challenge test for rats in the NOVEL, $\mathrm{HOME}^{+}$or $\mathrm{HOME}^{-}$ groups. A one-way ANOVA indicated a significant effect of group $(F=29.7, P<0.01)$. Rats in the NOVEL and $\mathrm{HOME}^{+}$groups that were pretreated with amphetamine showed a greater rotational response than their respective saline-pretreated groups, i.e. these groups showed a conditioned response (Fisher's PLSD, $P<0.05$ ). The magnitude of the conditioned response in the NOVEL ${ }^{(a)}$ group was greater than in the $\mathrm{HOME}^{+ \text {(a) }}$ group, as indicated by a significant interaction effect (two-way ANOVA, effect of pretreatment drug, $F=34.9, P<0.0001$; effect of condition, $F=40.2, P<0.0001$; effects of drug-by-condition, $F=8.5, P<0.01)$. Furthermore, the response of the $\mathrm{HOME}^{+(\mathrm{a})}$ and $\mathrm{HOME}^{- \text {(a) }}$ groups did not differ. 
with reports showing a rapid rise in plasma and brain concentrations of amphetamine and the extracellular concentrations of dopamine following intravenous injections in rats [24,28]. The effects of an acute intravenous injection of $0.5 \mathrm{mg} / \mathrm{kg}$ amphetamine can be seen by examining the data for test session 1 (Fig. 1A). There were large group differences in the effect of the first injection of amphetamine, as indicated by a oneway ANOVA. Both the NOVEL ${ }^{(a)}$ and $\mathrm{HOME}^{+(a)}$ groups made significantly more rotations after an injection of amphetamine than the saline control groups or

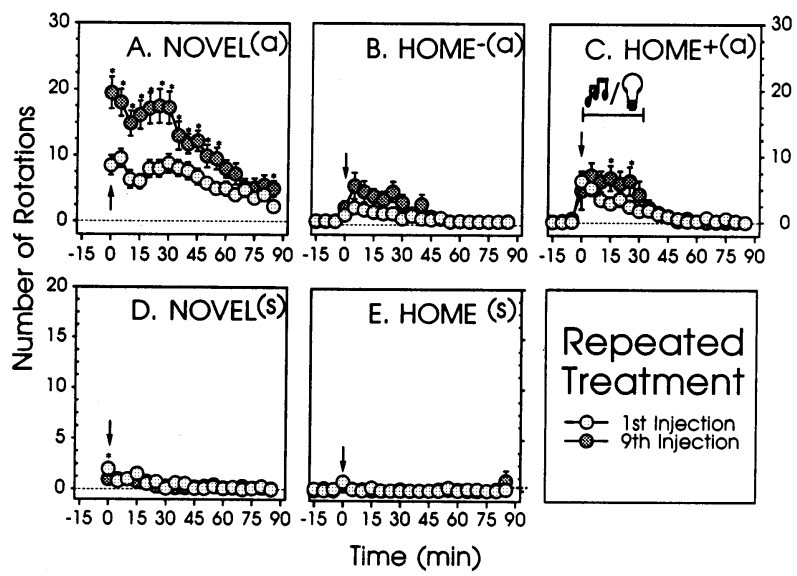

Fig. 2. The mean $( \pm$ S.E.M. $)$ number of rotations per 5-min interval in response to the first (light circles) and ninth (dark circles) injection of $0.5 \mathrm{mg} / \mathrm{kg}$ amphetamine (top panels) or saline (bottom panels) in the NOVEL, $\mathrm{HOME}^{+}$or $\mathrm{HOME}^{-}$groups. The asterisks indicate a significant $(P<0.05)$ difference in rotations between the first and ninth test session for each time interval (paired Student's $t$-tests).

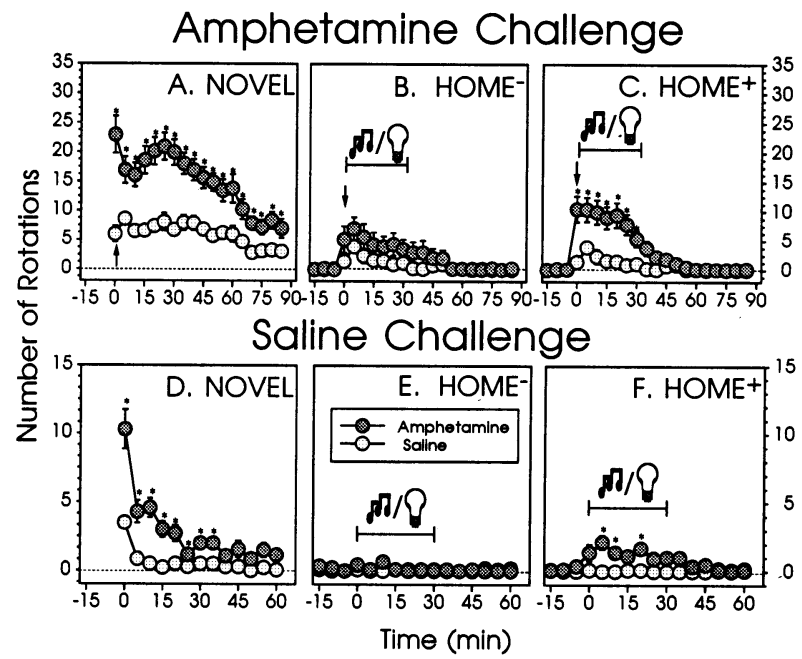

Fig. 3. The mean ( \pm S.E.M.) number of rotations per 5-min interval in response to a challenge injection of $0.5 \mathrm{mg} / \mathrm{kg}$ amphetamine (top panels) or saline (bottom panels). For both the $\mathrm{HOME}^{+}$and $\mathrm{HOME}^{-}$groups the saline and amphetamine challenge injections were paired with presentation of the light and tone stimuli. The asterisks indicate a significant $(P<0.05)$ difference in rotations between saline and amphetamine pretreated groups during each time interval (unpaired Student's $t$-tests). the $\mathrm{HOME}^{-(\mathrm{a})}$ group (Fisher's PLSD, $P<0.05$ ). In the latter group, amphetamine did not produce a significant increase in rotational behavior, relative to the saline control group. Furthermore, amphetamine had a greater acute effect in the NOVEL group than in the $\mathrm{HOME}^{+}$group. Inspection of the time course data shows that in the NOVEL condition the early peak in activity was followed by a small decline in rotations, followed by a second peak in activity $\approx 20-30 \mathrm{~min}$ after the injection (Fig. 2A). In contrast, in the $\mathrm{HOME}^{+ \text {(a) }}$ (and $\mathrm{HOME}^{- \text {(a) }}$ ) groups, amphetamine produced only a small and brief increase in rotational behavior and the response was characterized by a single initial peak in behavior, followed by a rapid return to baseline levels of activity (Fig. 2B,C).

The effects of repeated injections of amphetamine were assessed using linear regression analyses, and the results are shown in Fig. 1B. There were large group differences in the response to repeated injections of amphetamine. In the NOVEL ${ }^{(a)}$ group there was a progressive increase in rotational behavior across test sessions, as indicated by a significant positive slope (mean \pm S.E.M. slope coefficient $=13.26 \pm 2.65, \quad P<$ $0.001)$. In the $\mathrm{HOME}^{- \text {(a) }}$ or $\mathrm{HOME}^{+ \text {(a) }}$ groups repeated injections of amphetamine did not produce a statistically significant increase in rotations (i.e. the slopes were not different from 0 ), and these groups did not differ from each other (mean \pm S.E.M. slope coefficients: $\quad \mathrm{HOME}^{-(\mathrm{a})}=3.47 \pm 1.769, \quad P=0.10$, $\left.\mathrm{HOME}^{+(\mathrm{a})}=1.726 \pm 1.189, P=0.16\right)$. The time course data show that for the NOVEL ${ }^{(a)}$ group sensitization was characterized by a large increase in the magnitude of the initial behavioral response, which persisted throughout the first hour of the test session (Fig. 2A).

The mean number of rotations seen following the saline challenge were averaged over the first $15 \mathrm{~min}$ following injection (Fig. 1D), because this captured the entire time course of the conditioned response (Fig. 3, bottom panels). Both the NOVEL ${ }^{(a)}$ and $\mathrm{HOME}^{+(\mathrm{a})}$ groups showed a greater response than the saline control group, indicating that these groups developed a conditioned response (to contextual or discrete stimuli, respectively). The magnitude of the conditioned response, however, was significantly greater in the NOVEL $^{(a)}$ group than in the $\mathrm{HOME}^{+(\text {a) }}$ group, as indicated by a significant drug (pretreatment)-by-condition interaction (Fig. 1D). Also, the $\mathrm{HOME}^{+ \text {(a) }}$ group did not differ significantly from the $\mathrm{HOME}^{-(a)}$ group. As expected, the $\mathrm{HOME}^{-(a)}$ group did not show a conditioned response following presentation of the light/tone stimulus.

Finally, on the amphetamine challenge test session amphetamine-pretreated rats showed greater rotational behavior than saline-pretreated rats, in both the NOVEL $^{(a)}$ and HOME ${ }^{+(a)}$ groups (Fig. 1C). In other words, both groups sensitized to the psychomotor stim- 
ulant effects of amphetamine. However, the magnitude of the sensitized response was significantly greater in the NOVEL ${ }^{(a)}$ group than in the $\mathrm{HOME}^{+(\text {a) }}$ group, as indicated by a significant drug (pretreatment)-by-condition interaction. In both of these groups, behavioral sensitization was characterized by an increase in the early peak drug response (Fig. 3A and C). Note, however, that the $\mathrm{HOME}^{+}$(a) did not differ significantly from the $\mathrm{HOME}^{-(a)}$ group and this latter group did not show a significantly greater response than saline pretreated rats, confirming that these rats did not sensitize (Fig. 1C).

\section{Experiment 2}

Experiment 1 indicated that discrete drug-paired cues did not promote robust sensitization, but had only a very modest effect. It is possible, however, that the relatively small effect of discrete cues in promoting sensitization was because either the stimuli used were not optimal or there were too few pairings between drug injections and the drug predictive stimuli. In Experiment 2, therefore, we examined the effects of 20 (versus nine in Experiment 1) intravenous injections of amphetamine (or saline) in all groups. Additionally, the compound stimulus was modified in an attempt to increase its effectiveness. First, it is possible that in Experiment 1 the stimulus was not especially effective because of the overshadowing of one stimulus element (light) by the second element (the tone), a phenomenon sometimes observed with compound stimuli $[48,62]$. Therefore, in the present experiment we decided to use a compound stimulus consisting of alternating repetitions of a flashing light and a tone. Second, the temporal relationship between the stimulus and drug effect was altered so that cue presentation would better coincide with the peak drug effect, because this may promote more robust learning. Finally, in Experiment 1 we observed that some rats in the $\mathrm{HOME}^{-}$and $\mathrm{HOME}^{+}$ groups appeared to be inattentive during drug administration. Thus, in this experiment we devised a method to arouse the rats prior to drug administration and cue presentation by remotely vibrating the test cages.

\subsection{Methods}

The techniques and testing procedures were similar to those used in the previous experiment. Briefly, the following experimental groups were used: NOVEL ${ }^{(a)}$ $(N=11), \quad \mathrm{NOVEL}^{(\mathrm{s})} \quad(N=12), \mathrm{HOME}^{+(\mathrm{a})} \quad(N=9)$, $\mathrm{HOME}^{+(\mathrm{s})}(N=4), \mathrm{HOME}^{- \text {(a) }}(N=11)$, and finally HOME $^{-(\mathrm{s})}(N=4)$. Following the 5-day habituation phase, the rats received 20 daily intravenous injections of either $0.5 \mathrm{mg} / \mathrm{kg}$ amphetamine or saline. Again, each injection again consisted of $20 \mu \mathrm{l}$ of heparin, followed by $15 \mu \mathrm{l}$ of amphetamine solution $(0.5 \mathrm{mg} / \mathrm{kg})$ or saline followed by an additional $25 \mu \mathrm{l}$ of heparin solution. However, in this experiment the solution was injected at a flow-rate of $20 \mu \mathrm{l} / \mathrm{min}$, and therefore, the bolus of drug solution was injected over $45 \mathrm{~s}$. As in Experiment 1, both the $\mathrm{HOME}^{-}$and the $\mathrm{HOME}^{+}$groups were exposed to the compound stimulus consisting of alternating periods of a light stimulus (10 s), followed by a pulsing tone $(85 \mathrm{~dB}, 10 \mathrm{~s})$. For the $\mathrm{HOME}^{+}$groups the stimulus preceded drug (or saline) administration by 10 $\mathrm{s}$ and remained on for 10 min following drug administration. For the $\mathrm{HOME}^{-}$groups drug (or saline) administration and stimulus presentation were always unpaired, except during the challenge test, as in Experiment 1 . Finally, 1 min prior to stimulus onset (in the $\mathrm{HOME}^{+}$groups) or unsignaled drug administration (in the $\mathrm{HOME}^{-}$groups) the test cages were vibrated by remotely activating a small vibrator attached to each test cage (three pulses of $1 \mathrm{~s}$ duration each). Video observation confirmed that this technique alerted the animals prior to drug administration, as indicated by orienting movements and head scanning behavior. The NOVEL groups were handled and tested using identical procedures as described for Experiment 1.

Following a 10-day withdrawal period, all groups were given a challenge injection of $0.5 \mathrm{mg} / \mathrm{kg}$ amphetamine to test for the expression of sensitization. The day after this, all groups were tested for the development of a conditioned response by measuring rotational behavior in response to a challenge injection of saline. During the amphetamine and saline challenge tests drug administration for both the $\mathrm{HOME}^{-}$and $\mathrm{HOME}^{+}$groups was paired with presentation of the light/tone stimulus. Furthermore, for the saline challenge test the compound cue was presented continuously during the first hour of the test session.

Rotational behavior was recorded for $120 \mathrm{~min}$ in 5-min bins. For the $\mathrm{HOME}^{-}$and $\mathrm{HOME}^{+}$groups rotational behavior was recorded for an additional 15 min prior to drug administration to measure baseline activity.

\subsection{Results: Experiment 2}

Fig. 4 shows the effects of 20 intravenous infusions of $0.5 \mathrm{mg} / \mathrm{kg}$ of amphetamine or saline (panel A), a challenge infusion of $0.5 \mathrm{mg} / \mathrm{kg}$ amphetamine (panel C) or a challenge infusion of saline (panel D) given to rats: (i) after placement into the novel test environment (NOVEL); (ii) in the home cage where drug administration was signaled by discrete stimuli $\left(\mathrm{HOME}^{+}\right)$; or (iii) in the home cage where drug administration was unsignaled $\left(\mathrm{HOME}^{-}\right)$. For illustrative purposes Fig. 5 shows the time course of rotational behavior following the 1st and 20th injection of amphetamine (top panels) or saline (bottom panels) and Fig. 6 shows the time 

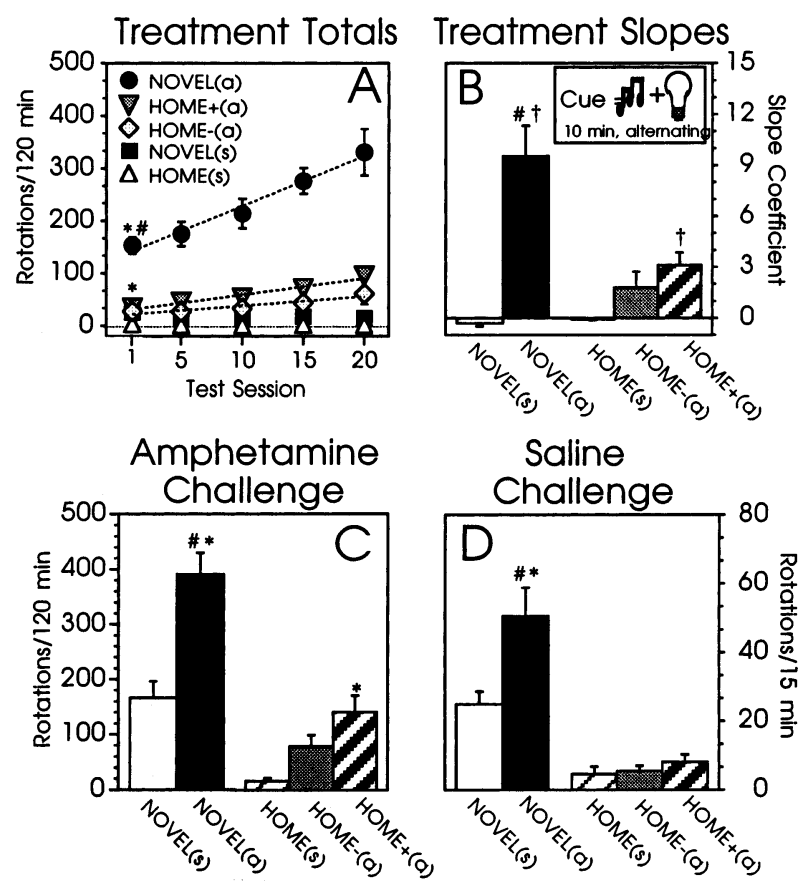

Fig. 4. (A) The mean ( \pm S.E.M. number of rotations during the first, fifth, tenth and twentieth test session for rats that received intravenous injections of saline or $0.5 \mathrm{mg} / \mathrm{kg}$ amphetamine. The groups are the same as in Fig. 1. The first and subsequent injections of saline produced negligible rotational behavior in all groups. A one-way ANOVA indicated that there was a significant effect of group during the first test session $(F=51.1, P<0.0001)$. The first injection of amphetamine produced a significant increase in rotational behavior in both the $\mathrm{NOVEL}^{(\mathrm{a})}$ and HOME ${ }^{+(\mathrm{a})}$ groups (Fisher's PLSD, $P<0.01$ ), but not in the $\mathrm{HOME}^{- \text {(a) }}$ group. Furthermore, the acute response to amphetamine was greater in the NOVEL ${ }^{(a)}$ group than in the $\mathrm{HOME}^{+(\text {a) }}$ group (Fisher's PLSD, $P<0.05$ ), and the latter group did not differ significantly from the $\mathrm{HOME}^{- \text {(a) }}$ group. (B) The results of the linear regression analyses indicated that the NOVEL (a) and $\mathrm{HOME}^{+(a)}$ groups showed an increase in rotations over test sessions, i.e. sensitization $\left(\right.$ NOVEL $^{(a)}$, mean \pm S.E.M. slope coefficient $=9.53, t=5.4, P<$ $0.001 ; \mathrm{HOME}^{+(\text {a) }}$, mean \pm S.E.M. slope coefficient $=3.10, t=4.1$, $P<0.01)$. However, the rate of sensitization in the NOVEL ${ }^{(a)}$ group was significantly greater than in the $\mathrm{HOME}^{+(a)}$ group $(t=4.5$, $P<0.05)$. Furthermore, the latter group did not differ significantly from the $\mathrm{HOME}^{-(a)}$ group. (C) Mean ( \pm S.E.M.) number of rotations on the amphetamine challenge day. A one-way ANOVA showed there was a significant effect of group $(F=23.1, P<0.0001)$. Rats in the NOVEL and $\mathrm{HOME}^{+}$groups, that were pretreated with amphetamine, showed a greater rotational response than their respective saline control groups (Fisher's PLSD, $P<0.05$ ). However, the magnitude of sensitization in the NOVEL ${ }^{(a)}$ group was greater than in the $\mathrm{HOME}^{+(a)}$ group, as indicated by a significant interaction effect (two-way ANOVA; effect of drug, $F=28.9, P<0.0001$; effect of condition, $F=36.5, P<0.0001$; effect of drug-by-condition, $F=4.1, P<0.05$ ). Also, the $\mathrm{HOME}^{+(\text {a) }}$ and $\mathrm{HOME}^{-(\text {a) }}$ groups did not differ significantly. (D) Mean ( \pm S.E.M.) number of rotations during the first 15 min of the saline challenge test. A one-way ANOVA showed a significant effect of group $(F=15.2, P<0.0001)$. Rats pretreated with amphetamine in the NOVEL (Fisher's PLSD, $P<0.0001$ ), but not in the $\mathrm{HOME}^{+}$or $\mathrm{HOME}^{-}$groups, showed a conditioned response.

course of rotational behavior during the amphetamine (top panels) and saline challenge tests (bottom panels).
Vibration of the test cages, presentation of the discrete cues, and injections of saline had no measurable effect on rotational behavior in the $\mathrm{HOME}^{-(\mathrm{s})}$ and $\mathrm{HOME}^{+(\mathrm{s})}$ groups and these groups did not differ from each other (Fig. 4A). Therefore, the data from these groups were pooled to yield a single control group $\left(\mathrm{HOME}^{(\mathrm{s})}\right)$. As in Experiment 1, exposure to the novel environment produced a small increase in activity during the first $10 \mathrm{~min}$ of the first test session, but this quickly habituated across test sessions (Fig. 5D).

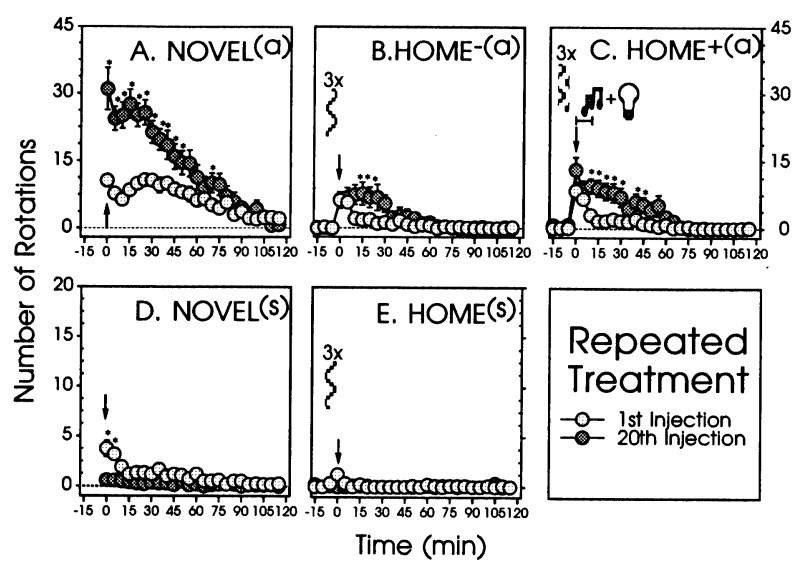

Fig. 5. The mean ( \pm S.E.M.) number of rotations per 5-min interval in response to the first (light circles) and twentieth injection (dark circles) of $0.5 \mathrm{mg} / \mathrm{kg}$ amphetamine (top panels) or saline (bottom panels) in the NOVEL, $\mathrm{HOME}^{+}$or $\mathrm{HOME}^{-}$groups. The asterisks indicate a significant $(P<0.05)$ difference in rotations between the first and twentieth test session for each time interval (paired Student's $t$-tests).

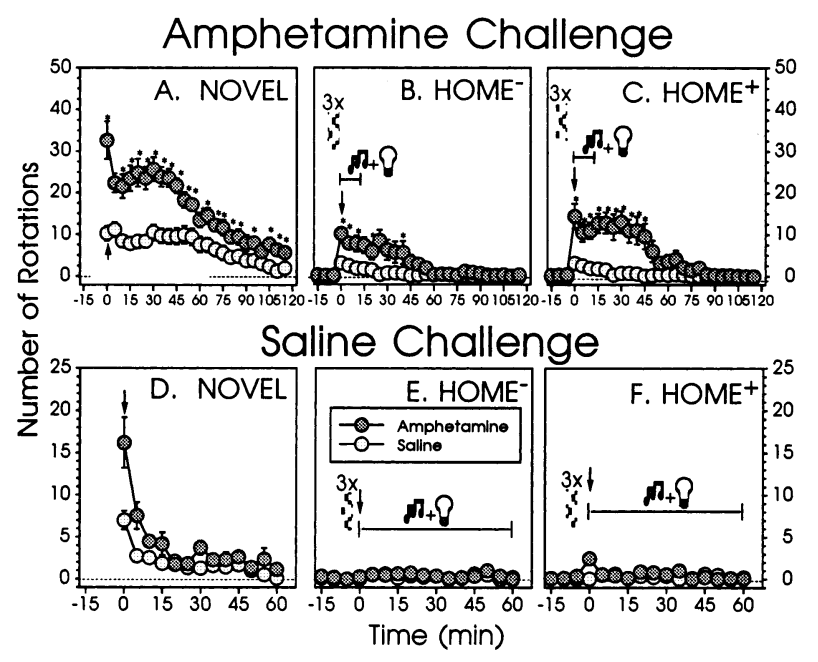

Fig. 6. The mean $( \pm$ S.E.M. $)$ number of rotations per 5-min interval in response to a challenge injection of $0.5 \mathrm{mg} / \mathrm{kg}$ amphetamine (top panels) or saline (bottom panels). For both the $\mathrm{HOME}^{+}$and $\mathrm{HOME}^{-}$ groups the saline and amphetamine challenge infusions were paired with presentation of the light and tone stimuli. The asterisks indicate a significant $(P<0.05)$ difference in rotations between saline and amphetamine pretreated groups during each time interval (unpaired Student's $t$-tests). 
There was again a large effect of treatment condition on the acute response to amphetamine (Fig. 4A, test session 1). In the NOVEL ${ }^{(a)}$ group the first injection of amphetamine produced a large increase in rotational behavior, which was significantly greater than that observed in all other groups $(P<0.01)$. When the treatment was preceded by the compound stimulus in the home cages $\left(\mathrm{HOME}^{+(\mathrm{a})}\right)$, amphetamine produced a small, but statistically significant increase in rotational behavior, relative to the saline control group and this was significantly greater than that seen in the $\mathrm{HOME}^{- \text {(a) }}$ group (Fisher's PLSD tests, $P<0.05$ ). The latter group did not show a significant increase in rotational behavior relative to the saline control group.

As in Experiment 1, repeated injections of amphetamine given in a distinct test cage $\left(\right.$ NOVEL $\left.^{(a)}\right)$ produced robust sensitization, as indicated by a significant positive slope coefficient (Fig. 4B; mean \pm S.E.M. slope coefficient for the NOVEL ${ }^{(a)}$ group $=9.538 \pm$ 1.774, $P<0.0001)$. Amphetamine treatments signaled by a discrete stimulus in the home cages also induced sensitization (mean \pm S.E.M. slope coefficient for the $\mathrm{HOME}^{+ \text {(a) }}$ group $=3.103 \pm 0.75, P<0.05$ ). However, the rate of sensitization in the NOVEL ${ }^{(a)}$ group was significantly greater than in the $\mathrm{HOME}^{+(a)}$ group, as indicated by a significant difference in slope coefficients $(P<0.05$, Fig. 4B). This difference in sensitization is also reflected in the time course data shown in Fig. 5. After repeated amphetamine treatment animals in the NOVEL ${ }^{(a)}$ group showed a much greater peak behavioral response and the response was more persistent than that seen in the $\mathrm{HOME}^{+(a)}$ group (see Fig. 5A,C). Furthermore, the slope coefficients for the $\mathrm{HOME}^{-(a)}$ were not different from zero (i.e. they did not sensitize) and the $\mathrm{HOME}^{+(\mathrm{a})}$ and $\mathrm{HOME}^{- \text {(a) }}$ groups did not differ.

The results of the amphetamine challenge test were consistent with the treatment phase of the experiment (Fig. 4C). Amphetamine-pretreated rats in the NOVEL and $\mathrm{HOME}^{+}$conditions both showed a greater rotational response to a challenge injection of $0.5 \mathrm{mg} / \mathrm{kg}$ amphetamine than did saline-pretreated rats, indicating that these groups sensitized. However, the NOVEL (a) group showed greater sensitization than the $\mathrm{HOME}^{+(a)}$ group, as indicated by a significant drug (pretreatment)by-condition interaction $(P<0.05)$. The $\mathrm{HOME}^{- \text {(a) }}$ group did not differ significantly from the saline control group or from the $\mathrm{HOME}^{+(a)}$ group.

As in Experiment 1, the rats pretreated with amphetamine in the distinct test environment showed a conditioned response when given a challenge injection of saline in the drug treatment environment (Fig. 4D and Fig. 6D). In contrast, rats in the $\mathrm{HOME}^{-}$and $\mathrm{HOME}^{+}$conditions did not show a significant conditioned response upon presentation of the compound stimulus (Fig. 6E,F). The absence of a $\mathrm{CR}$ in the
$\mathrm{HOME}^{+}$(a) group might be due to the fact that in this experiment the saline control group showed a relatively large rotational response (compare Fig. 1D for Experiment 1 and Fig. 4D for this experiment). It is possible, therefore, that the single pairing between amphetamine and the compound stimulus during the amphetamine challenge test was sufficient to produce a conditioned response (Ref. [23] for example). (Note that in this experiment the saline challenge test was given after the amphetamine challenge test).

\section{Experiment 3}

The results of Experiments 1 and 2 indicate that signaling drug administration with a discrete stimulus does not promote robust psychomotor sensitization comparable to that seen when amphetamine treatments are given in a distinct and relatively novel test environment. It is possible, however, that contextual stimuli were especially effective because the test context, in addition to visual and auditory stimuli, also provided olfactory cues (e.g. the smell of the corn-cob bedding), which are a particularly effective CS for rats. Indeed, Ferger et al. [33] reported that olfactory stimuli, but not visual or tactile stimuli, elicited a large excitatory conditioned response following pairing with injections of apomorphine. Similarly, olfactory cues have been reported to provide superior discriminative stimulus properties in drug self-administration experiments $[50,86]$. Therefore, in Experiment 3 we used a compound stimulus consisting of a simultaneously presented pulsing tone and an odor.

\subsection{Methods}

Again, the methods and procedures were similar to those used in Experiments 1 and 2. Briefly, the following groups were tested: NOVEL ${ }^{\text {(a) }}(N=7 / 6)$, NOVEL ${ }^{(\mathrm{s})}$ $(N=8), \quad \mathrm{HOME}^{+ \text {(a) }}(N=9 / 8), \mathrm{HOME}^{+(\mathrm{s})}(N=5)$, $\mathrm{HOME}^{-(\mathrm{a})}(N=9)$ and finally $\mathrm{HOME}^{-(\mathrm{s})}(N=4)$. Two rats passed a catheter patency test given after the last treatment day, but failed the catheter patency test given at the end of the experiment. Therefore, their data were used to analyze the acute drug response, and the development of sensitization, but were excluded from the statistical analyses of the amphetamine and saline challenge tests. The treatment phase consisted of nine consecutive daily i.v. infusions of $0.5 \mathrm{mg} / \mathrm{kg}$ amphetamine or saline, delivered at a flow-rate of 20 $\mu 1 / \mathrm{min}$. The compound stimulus used to signal drug administration in the HOME groups consisted of the following. First, the experimenter entered the testing room and placed a cotton-tip applicator, which had been impregnated with a peppermint concentrate (dissolved in $90 \%$ ethanol), into a small container mounted 

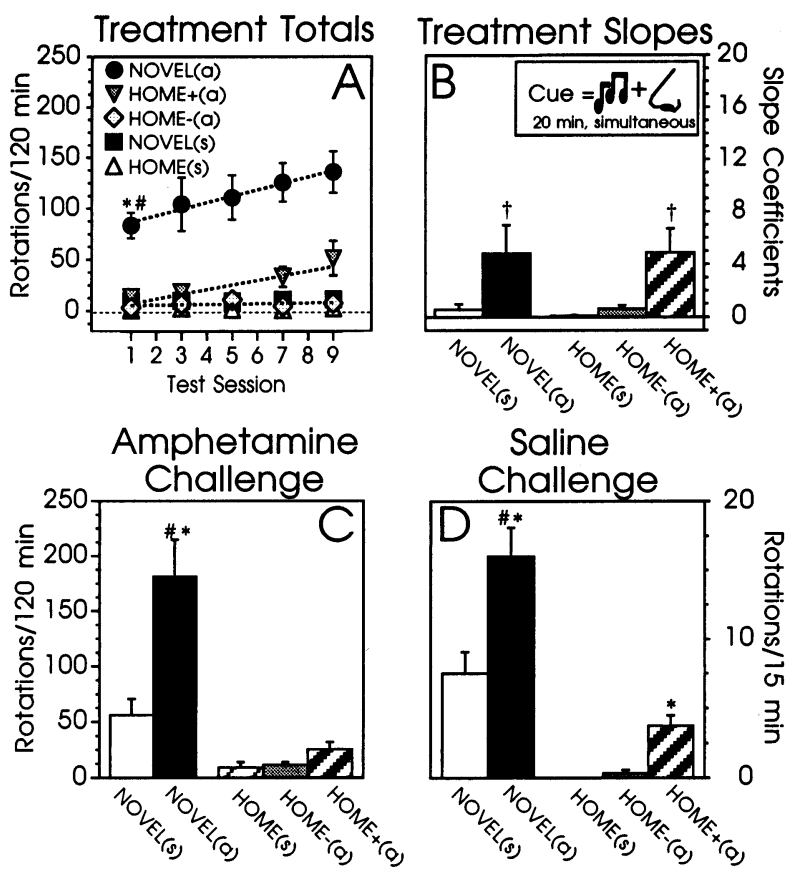

Fig. 7. (A) The mean number of rotations ( \pm S.E.M.) during the first, third, fifth, seventh and ninth test session for rats that received intravenous injections of saline or $0.5 \mathrm{mg} / \mathrm{kg}$ amphetamine. The groups are the same as in Fig. 1. The first and subsequent injections of saline produced negligible rotational behavior in all groups. There were significant group differences on the first test day $(F=33.6$, $P<0.0001)$. An acute injection of amphetamine produced a significant increase in rotational behavior in the NOVEL group (Fisher's PLSD $P<0.0001$ ), but not in the $\mathrm{HOME}^{+}$or $\mathrm{HOME}^{-}$groups. (B) Presents the results of the linear regression analyses for all groups. One-sample $t$-tests indicated that repeated injections of amphetamine in the NOVEL ${ }^{\text {(a) }}$ (mean \pm S.E.M. slope coefficient $=4.8, t=2.3, P<$ 0.05 ) and $\mathrm{HOME}^{+(\text {a) }}$ (mean \pm S.E.M. slope coefficient $=4.9, t=3.1$, $P<0.05)$ groups produced a significant increase in rotations over test sessions, i.e. these groups sensitized. Also, these groups did not differ from one another. (C) Mean number of rotations ( \pm S.E.M.) in response to an amphetamine challenge injection. A one-way ANOVA indicated that there was a significant effect of group $(F=18.3$, $P<0.0001$ ). Rats in the NOVEL(a) group (Fisher's PLSD, $P<$ 0.0001 ), but not in the $\mathrm{HOME}^{+}$(a) and $\mathrm{HOME}^{- \text {(a) }}$ groups showed a sensitized response. (D) Mean number of rotations ( \pm S.E.M.) during the first $15 \mathrm{~min}$ of the saline challenge test. A one-way ANOVA showed a significant effect of group $(F=39.7, P<0.0001)$. Rats pretreated with amphetamine in the $\operatorname{NOVEL}^{\text {(a) }}$ and $\mathrm{HOME}^{+(\text {a) }}$ groups (Fisher's PLSD, $P<0.05$ ) showed a conditioned response, and there was no significant difference in the magnitude of the conditioned response between these groups.

over a small hole in the wall of each test cage. At the same time the odor stimulus was introduced, the background white noise signal was turned off and a pulsing tone $(85 \mathrm{~dB})$ was turned on. For the $\mathrm{HOME}^{+}$groups the cue was introduced $1 \mathrm{~min}$ prior to drug administration. Following drug administration $(20 \mathrm{~min})$ the cotton tips were removed from the test cages, the pulsing tone was switched off and white noise resumed. For $\mathrm{HOME}^{-}$groups cue presentation and drug administration were always unpaired (except during the challenge tests) using the same procedure as in Experiments 1 and 2. Also, the NOVEL groups were treated as in Experiments 1 and 2 (i.e. no tone/olfactory cue was presented).

Following a 6-day withdrawal period all groups received a challenge i.v. infusion of $0.5 \mathrm{mg} / \mathrm{kg}$ of amphetamine to test for the expression of sensitization, and the following day a challenge injection of saline was given to test for the development of a conditioned rotational response. For the $\mathrm{HOME}^{-}$and $\mathrm{HOME}^{+}$ groups, the challenge injections were again paired with the presentation of the compound stimulus (on the saline challenge test the cue was presented throughout the entire test session).

Rotational behavior was recorded for $90 \mathrm{~min}$ in 5 min bins. For the $\mathrm{HOME}^{-}$and $\mathrm{HOME}^{+}$groups rotations were recorded for an additional $15 \mathrm{~min}$ prior to drug administration.

\subsection{Results: Experiment 3}

Fig. 7 shows the effects of nine intravenous infusions of $0.5 \mathrm{mg} / \mathrm{kg}$ amphetamine or saline (panel A), a challenge infusion of $0.5 \mathrm{mg} / \mathrm{kg}$ amphetamine (panel C) or a challenge injection of saline (panel D). For illustrative purposes Fig. 8 shows the time course of rotational behavior following the first and ninth injection of amphetamine (top panels) or saline (bottom panels) and Fig. 9 shows the time course of rotational behavior during the amphetamine (top panels) and saline challenge tests (bottom panels).

The first injection of saline in the NOVEL environment again produced a small increase during the first 5 min of the test session, but in contrast to previous experiments this effect did not disappear with repeated

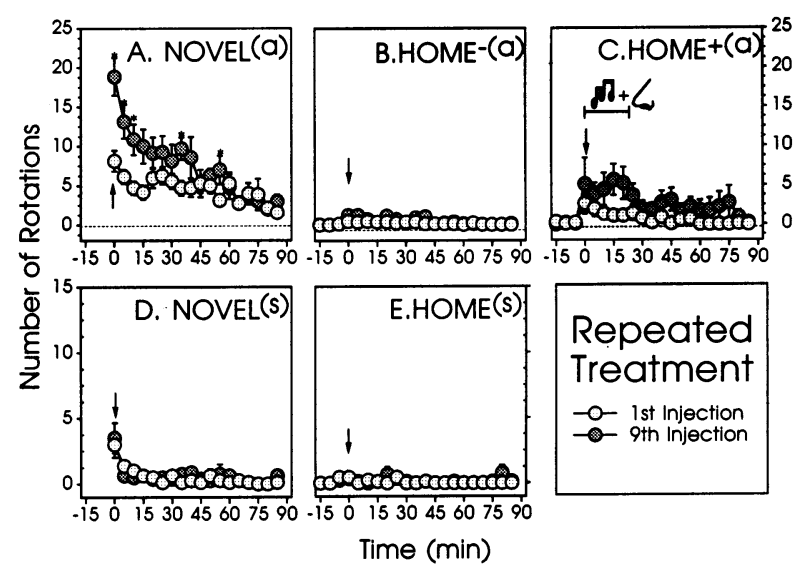

Fig. 8. The mean ( \pm S.E.M.) number of rotations per 5-min interval in response to the first (light circles) and ninth injection (dark circles) of $0.5 \mathrm{mg} / \mathrm{kg}$ amphetamine (top panels) or saline (bottom panels). The asterisks indicate a significant $(P<0.05)$ difference in rotations between the first and ninth test session for each time interval (paired Student's $t$-tests). 


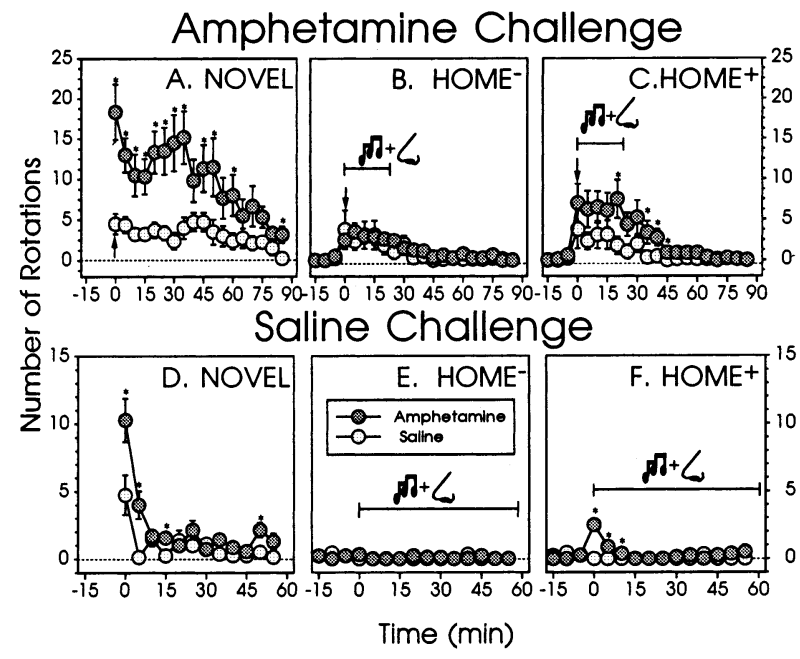

Fig. 9. The mean $( \pm$ S.E.M. $)$ number of rotations per 5 -min interval in response to a challenge injection of $0.5 \mathrm{mg} / \mathrm{kg}$ amphetamine (top panels) or saline (bottom panels). For both the $\mathrm{HOME}^{+}$and $\mathrm{HOME}^{-}$groups the saline and amphetamine challenge injections were paired with presentation of the tone and odor stimuli. The asterisks indicate a significant $(P<0.05)$ difference in rotations between saline and amphetamine pretreated groups during each time interval (unpaired Student's $t$-tests)

exposure to the novel test environment (Fig. 8D). There were no differences between the $\mathrm{HOME}^{-(\mathrm{s})}$ and $\mathrm{HOME}^{+(\mathrm{s})}$ groups at any time and therefore, these data were pooled to yield a single control group $\left(\mathrm{HOME}^{(\mathrm{s})}\right)$.

There was a large effect of treatment condition on the acute response to amphetamine (Fig. 7A, 1st test session). The first injection of amphetamine produced a large response in the NOVEL ${ }^{(a)}$ group, and this was significantly greater than in all other groups (Fisher's PLSD tests, $P<0.01)$. In contrast, there was no effect of the first amphetamine injection in either the $\mathrm{HOME}^{+ \text {(a) }}$ or $\mathrm{HOME}^{- \text {(a) }}$ groups; i.e. they did not differ from the $\mathrm{HOME}^{(\mathrm{s})}$ group, or from each other.

As in Experiment 2, repeated injections of amphetamine produced a progressive increase in rotational activity across test sessions in both the NOVEL ${ }^{(a)}$ and $\mathrm{HOME}^{+}$(a) groups (Fig. 7A,B), indicating that these groups sensitized. Furthermore, these groups did not differ in the rate of sensitization, as indicated by similar slope coefficients $\left(\right.$ NOVEL $^{(a)}$ group $=4.84 \pm 2.14, P<$ $0.05 ; \mathrm{HOME}^{+(a)}$ group $=4.88 \pm 1.80, \quad P<0.05$ ). It should be noted, however, that the slope calculated for the NOVEL ${ }^{(a)}$ group was unexpectedly small, relative to the slopes obtained in the previous experiments. Therefore, is seems reasonable to suggest that the similarity in slopes in the NOVEL ${ }^{\text {(a) }}$ and $\mathrm{HOME}^{+(\text {a) }}$ groups was the result of a reduced rate of sensitization in the NOVEL ${ }^{(a)}$ group, rather than to an increase in sensitization in the $\mathrm{HOME}^{+(a)}$ group. It is unclear why amphetamine did not produce more robust within-subjects sensitization in the NOVEL group in this experi- ment (but see below). Repeated treatments with amphetamine again did not produce sensitization in the $\mathrm{HOME}^{-(\mathrm{a})}$ group, which differed significantly from the NOVEL $^{(a)}$ and $\mathrm{HOME}^{+(\text {a) }}$ groups $(P<0.05)$.

The amphetamine challenge test indicated that rats in the NOVEL ${ }^{(a)}$ group developed robust sensitization, whereas the HOME+(a) group did not (Fig. 7C). These results provide support for the hypothesis discussed above that amphetamine did not produce robust sensitization in the $\mathrm{HOME}^{+ \text {(a) }}$ group and that for some reason sensitization in the NOVEL ${ }^{\text {(a) }}$ was unusually attenuated during the treatment phase of the experiment. Rats in the $\mathrm{HOME}^{- \text {(a) }}$ condition again did not show evidence of sensitization.

The effect of the saline challenge test illustrate that amphetamine-pretreated rats in both the NOVEL ${ }^{(a)}$ and $\mathrm{HOME}^{+ \text {(a) }}$ groups, but not the $\mathrm{HOME}^{- \text {(a) }}$ group, showed a conditioned response during the first $15 \mathrm{~min}$ of the test session (Fig. 7D and Fig. 9E,F). Furthermore, there was no significant difference in the magnitude of the conditioned response between the NOVEL $^{(a)}$ and $\mathrm{HOME}^{+(\text {a) }}$ groups, as indicated by a non-significant drug (pretreatment)-by-condition interaction (Fig. 7D).

\section{Experiment 4}

Taken together, the results presented thus far suggest that pairing discrete stimuli with drug administration in the home cage is not sufficient to promote the kind of robust sensitization seen when drug administration is paired with placement of the animal into a distinct test environment. Negative results are always troublesome, however, because it is not possible to "prove the negative'. For example, it is possible that the stimuli we used were simply not salient to the rats (see Section 8). Therefore, in a final attempt we decided to test whether a highly salient, fear-evoking cue (a tone previously paired with footshock) would promote more robust sensitization. These experiments are very labor and time demanding, therefore, in this experiment sensitization was assessed using only a within-subjects comparison and two groups: (i) rats that received repeated intravenous injections of amphetamine in the home cages in association with a cue previously paired with footshock $\left(\mathrm{HOME}^{+ \text {fearful(a) }}\right)$; and (ii) rats that received amphetamine injections in association with a cue that had not been paired with footshock $\left(\mathrm{HOME}^{+(a)}\right)$.

\subsection{Methods}

Following 6-OHDA lesions (but prior to catheter implantation) rats were housed in the drug treatment environment for 12 days. During this phase, half of the rats $(N=8)$ underwent a series of white noise and 
footshock pairings to establish first-order conditioning to the auditory cue. For the other half of the rats the auditory stimulus and shock were unpaired $(N=8)$. The first in a series of six consecutive daily sessions of fear conditioning began on day 3. Two fear conditioning cages were built from plastic round buckets identical to those used as drug test cages, except the floor of each conditioning cage was made of tubular steel rods (4 mm, diameter) spaced $1.9 \mathrm{~cm}$ apart. The grid floor was wired to a shock source and solid-state grid scrambler (Med. Associates, LaFayette, IN), which was programmed to deliver a 1-s, $1.6 \mathrm{~mA}$ footshock (US). The CS consisted of $60 \mathrm{~s}$ of white noise $(80 \mathrm{~dB})$ that was delivered through a speaker mounted to the side of each cage ( $\approx 4 \mathrm{~cm}$ above the grid floor). The cages were cleaned with water and $70 \%$ ethanol and the trays containing ground corn-cob bedding were placed underneath the grid floors. For each session the rats were transported in pairs from their home cages to the fear conditioning cages located in a nearby testing room. After placement into the cage $(3 \mathrm{~min})$, the rats assigned to the $\mathrm{HOME}^{+ \text {fearful(a) }}$ group received a 1 min presentation of the white noise stimulus immediately followed by a single footshock. The white noise-shock trial was repeated 10 times with a 120-s inter-shock interval, after which the rats were returned to their home cages. Rats assigned to the $\mathrm{HOME}^{+(a)}$ group $(N=8)$ also received ten footshocks and white noise presentations, but the temporal relationship between the white noise and footshock varied in two ways: either ten consecutive $1 \mathrm{~min}$ white noise presentations (30-s inter-tone interval) were followed by ten consecutive footshocks ( 1 min inter-shock interval), or ten footshocks were followed by ten white noise presentations. To reduce the

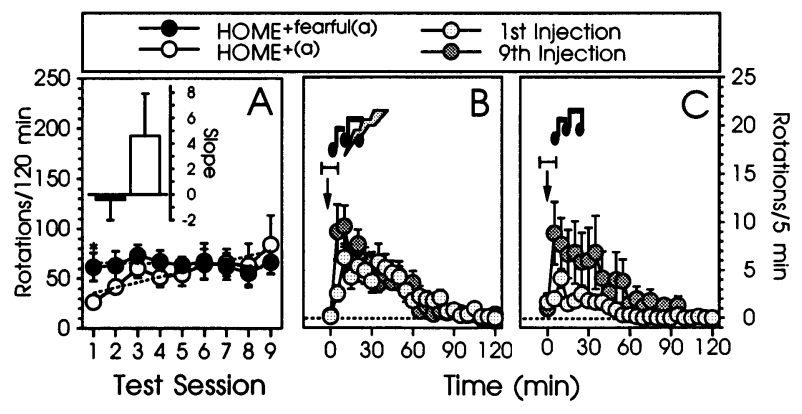

Fig. 10. (A) The mean number ( \pm S.E.M.) rotations during nine test sessions for rats that received injections of $0.5 \mathrm{mg} / \mathrm{kg}$ amphetamine that were signaled by a white noise stimulus that had previously been paired with footshock (HOME ${ }^{+ \text {fearful(a) }}$ ), or by a white noise stimulus that had not been paired with footshock $\left(\mathrm{HOME}^{+(\mathrm{a})}\right)$. The insert shows the slope coefficients. The first injection of amphetamine produced a significantly greater response when paired with a fearful stimulus than when paired with a neutral stimulus (unpaired $t$-test; $t=2.2, P<0.05$ ). However, neither of these groups showed a significant increase in rotational behavior over test sessions. (B and C) The number of rotations for each $5 \mathrm{~min}$ interval during the first and last test session. likelihood that conditioned fear to the white noise became dependent on contextual cues (including transport and handling), rats were also exposed at a various times before and during the fear conditioning phase to the apparatus, but no footshock or white noise were presented.

On the day following the final fear conditioning session (day 9) all rats were implanted with intravenous catheters. Rats were allowed to recover from surgery in their home cages for 3 days before the drug treatment phase of the experiment began. Catheters were flushed daily with $0.1 \mathrm{ml}$ of heparin solution. During the treatment phase, both groups received nine consecutive daily intravenous infusions of $0.5 \mathrm{mg} / \mathrm{kg}$ of amphetamine using injection procedures described above $(20 \mu \mathrm{l}$ heparin $+15 \mu l$ amphetamine $+45 \mu l$ heparin injected at a flow rate of $20 \mu \mathrm{l} / \mathrm{min}$ over a $3 \mathrm{~min}$ period). For both groups drug injection was accompanied by three 60 -s presentations of the white noise CS $(5 \mathrm{~min}$ before the treatment, at the moment of treatment and 5 min after the treatment). Thus, for one group drug administration was signaled by a cue that had been previously paired with footshock $\left(\mathrm{HOME}^{+ \text {fearful(a) }}\right)$, and for the other group drug administration was signaled by a cue that had not been paired with footshock $\left(\mathrm{HOME}^{+(a)}\right)$. As in Experiment 2, the cages were vibrated to be sure that rats were alert during white noise presentation and drug administration. Finally, following a 6 day withdrawal period both groups were given an additional i.v. challenge infusion of $0.5 \mathrm{mg} / \mathrm{kg}$ amphetamine to test for the long-term expression of sensitization.

\subsection{Results: Experiment 4}

Fig. 10 (panel A) shows the effects of nine intravenous injections of amphetamine in the $\mathrm{HOME}^{+ \text {fearful }}$ and $\mathrm{HOME}^{+(\text {a) }}$ groups (slope coefficients are presented in the inset). The first injection of amphetamine produced a significantly larger acute response when drug administration was preceded by the fearful cue than when preceded by the neutral cue (Fig. 10A). Although no attempt was made to quantify the response to the CS, casual observation revealed that rats for whom the white noise had previously been paired with footshock initially exhibited a conditional fear response, consisting of freezing behavior. Repeated injections of amphetamine did not produce a significant increase in rotational behavior over test sessions in either group (mean \pm S.E.M. slope coefficient for the: $\mathrm{HOME}^{+ \text {fearful(a) }}$ group $=-0.39 \pm 1.6$; for the $\mathrm{HOME}^{+}$(a) group $=4.59 \pm 3.29$ ), and the slopes for the two groups did not differ significantly. Thus, neither fearful nor neutral cues were sufficient to promote psychomotor sensitization when amphetamine was given in the HOME environment. Furthermore, these groups did not differ in their rotational response to a 


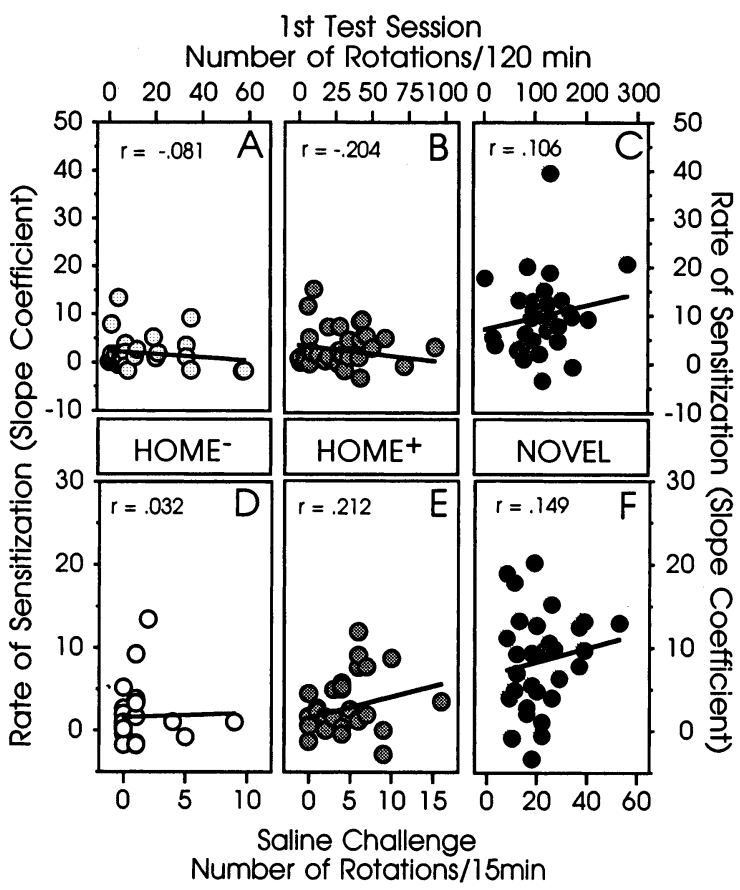

Fig. 11. (Top panels) The relationship between the acute response to amphetamine (first test session) and sensitization (slope coefficients) for all three treatment conditions calculated by conducting linear correlation analysis on the pooled data from Experiments 1-3. There were no significant correlations between the acute response to amphetamine and the rate of sensitization in any of the treatment conditions (Fisher's $r$ values: $\operatorname{NOVEL}^{(a)}=0.1, \quad P=0.57$; $\mathrm{HOME}^{+(\mathrm{a})}=-0.204, \quad P=0.25 ; \quad \mathrm{HOME}^{-(\mathrm{a})}=-0.08, \quad P=0.69$ ). (Bottom panels) The relationship between the conditioned response (Saline challenge) and sensitization (slope coefficients) for all treatment conditions. There were no significant correlations between the magnitude of the conditioned response and the rate of sensitization in any of the treatment conditions (Fisher's $r$ values: NOVEL $^{(a)}=0.15$, $P=0.42 ; \mathrm{HOME}^{+(\text {a) }}=0.212, P=0.25 ; \mathrm{HOME}^{-(\mathrm{a})}=0.032, P=$ $0.87)$.

challenge injection of amphetamine given after 6 days withdrawal.

\section{The relationship between the initial drug response, the development of a conditioned response, and the susceptibility to sensitization}

It has been suggested that the effect of environment (home versus novel) on the initial (acute) psychomotor response to amphetamine and on psychomotor sensitization can be dissociated [5]. To further explore this issue, linear correlation analyses were conducted on the combined data from Experiments 1-3. Fig. 11 (top panels) presents the results of these analyses and shows that there were no significant correlations between the initial drug response and the within-subjects measure of sensitization (slope coefficients) in any group.

Fig. 11 (bottom panels) shows similar analyses and demonstrates that the degree of behavioral sensitization (slope coefficients) was not significantly related to the magnitude of the conditioned response on the saline challenge day.

\section{Discussion}

In most experiments on sensitization there are many contextual stimuli associated with drug treatments that reliably predict drug administration, including removal from the home cage, handling, transport to a distinct test environment, stimuli associated with the drug injection ritual and interoceptive cues produced by the drug itself. As Siegel ([85], p. 84) has noted, 'in the absence of special precautions, the effects of a drug are almost always signaled by cues uniquely present at the time of drug administration. For example, piercing the skin with a hypodermic needle (in the case of parenterally administered drugs) reliably announces subsequent pharmacological stimulation'. These cues can have a large influence on the behavioral effects of psychostimulant drugs. For example, doses of amphetamine, cocaine or morphine that induce robust sensitization when given in a distinct test environment, may fail to induce sensitization when given in the absence of any environmental cues predictive of drug administration $[11,18,19,26,78]$. When higher doses of amphetamine or cocaine are administered, however, robust sensitization is induced, regardless of environmental context. That is, it appears that environmental context shifts the dose-effect curve for the induction of sensitization $[18,19]$. This effect of context is not unique to rotational behavior in rats with a unilateral lesion of the mesostriatal dopamine pathway, because a similar effect is found when the psychomotor stimulant effects of amphetamine are quantified by measuring locomotor crossover activity in neurologically intact rats $[5,36]$. In the present series of experiments, we sought to further examine the contribution of treatment-related stimuli in the induction of sensitization. Specifically, we compared the ability of contextual cues (a distinct test environment) versus discrete cues (light, tone and/or odor), paired with drug administration, to modulate the induction of sensitization.

The following major findings are reported. (i) Consistent with our previous studies (above for references), repeated intravenous infusions of $0.5 \mathrm{mg} / \mathrm{kg}$ amphetamine produced robust psychomotor sensitization when drug administration was signaled by placement into a distinct test environment. (ii) The same treatment regimen failed to produce sensitization when amphetamine was given at home in the absence of any environmental cues predictive of drug administration. (iii) When drug treatments were given in the home cage, but were signaled by discrete cues, only modest sensitization was seen. That is, using a within-subjects anal- 
ysis, sensitization was seen in the $\mathrm{HOME}^{+(\text {a) }}$ group in Experiments 2 and 3 (but not Experiment 1) and using a between-subjects analysis, sensitization was seen in Experiments 1 and 2 (but not Experiment 3). However, in all experiments the magnitude of sensitization in the $\mathrm{HOME}^{+(\text {a) }}$ group was significantly less than that in the NOVEL $^{(a)}$ group, and there were no significant differences between the $\mathrm{HOME}^{+ \text {(a) }}$ and $\mathrm{HOME}^{- \text {(a) }}$ groups on the amphetamine challenge test in any experiment. Taken together, these findings suggest that merely providing discrete stimuli predictive of drug administration in the home cage is not sufficient to promote the robust psychomotor sensitization observed when drug treatments are given in a distinct and relatively novel test environment.

The present findings are consistent with a number of earlier experiments from our group in which rats were given intraperitoneal injections of amphetamine or cocaine in either a distinct test environment or in physically identical cages in which the rats lived [5-7]. In these experiments there were a number of cues that reliably signaled drug administration even when drugs were given at home (e.g. the experimenter entering the testing room, handling and a needle jab). Rats treated under these conditions did sensitize, but to a much lesser extent than when drug treatments were given in a distinct and relatively novel test environment. Indeed, the discrete cues used in the present study and the cues associated with intraperitoneal injections are similar in many respects. For example, both are relatively simple discrete foreground stimuli that are presented only transiently; i.e. they precede and/or only partially overlap with the initial pharmacological effects of the drug. In contrast, by their very nature, contextual cues represent a global, multidimensional stimulus complex, including both foreground and background cues, some of which precede drug administration by minutes (e.g. handling and transport), and many of which extend beyond the initial pharmacological effects of the drug.

\subsection{Facilitation of associative learning processes by environmental context}

As in the case of contextual control over the expression of sensitization [1], it is not known how environmental stimuli gain access to the neural substrate that is sensitized by psychostimulant drugs to modulate the induction of sensitization [78]. As suggested in the Introduction, it is possible that exposure to a distinct test environment promotes robust sensitization because it facilitates associative learning processes [63,70,91]. Indeed, the current results appear to be consistent with such an associative learning view of sensitization. Although contextual and discrete cues both elicited a 'drug-like' CR following repeated drug treatments, the CR was typically more robust when contextual cues signaled drug administration than when discrete cues signaled drug administration (except Experiment 3). It is possible, therefore, that sensitization was facilitated in a distinct test environment because contextual stimuli were simply more effective CSs, relative to discrete stimuli, i.e. the 'associability' was greater for contextual stimuli than for discrete stimuli. If this is the case, however, we need to ask why contextual cues associated with drug treatments are more effective CSs than discrete cues, and thereby promote more robust psychomotor sensitization.

Unfortunately, the published literature provides little help. There are numerous reports demonstrating drug conditioning when contextual stimuli are used (for example see Refs. [14,22,29,30,45,67,69,80,90]), but only a few researchers have attempted to investigate the ability of discrete stimuli to acquire CS properties when the drugs are administered by the experimenter. Conditioned locomotor activity in response to discrete auditory $[14,17]$ or olfactory [33] stimuli paired with injections of amphetamine or apomorphine have been reported, as has conditioned analgesia after pairing an olfactory stimulus with injections of morphine [93]. The difficulty in interpreting these studies, however, is that during conditioning the discrete stimuli were embedded in a larger context (i.e. drug treatments were given a distinct test environment). Therefore, these studies probably demonstrate drug conditioning to both discrete and contextual stimuli. Indeed, this procedure may potentiate the 'associability' of discrete stimuli [4]. To the best of our knowledge only two studies have been reported in which discrete cues alone have been paired with experimenter-administered drug. Pickens and Dougherty [66], who used a procedure very similar to ours, described a 'chronic jugular catheter system, which allowed the drug to be injected automatically without interfering with the animal's normal cage movements'. They reported conditioned locomotor activity elicited by a discrete cue (light) after repeated pairings of the light with methamphetamine administration. Unfortunately, these authors reported data from only two rats. More recently, Panlilio and Schindler [61] reported that discrete cues (tone or light) paired with injections of cocaine developed the ability to elicit a conditioned locomotor response. Interestingly, these authors also reported that the expression of cocaine-induced sensitization came under conditioned control of the discrete stimulus. Neither of these two studies, however, directly compared drug conditioning using contextual versus discrete stimuli, let alone investigated differences in the ability of such stimuli to promote the induction of sensitization.

Nonetheless, there are a number of reasons why contextual stimuli associated with amphetamine administration might provide a more effective CS and gain more associative control over the induction of sensitiza- 
tion than discrete stimuli. First, contextual cues associated with the distinct test environment may have been more salient than discrete cues. According to the Rescorla-Wagner model of associative learning [71] changes in associative strength produced by a CS-US pairings are dependent, among other things, on the salience of the CS (Ref. [48] as well). One can imagine that being taken from the home cage, transported and then placed into a test environment consisting of many distinctive stimuli, including olfactory, visual, auditory and tactile stimuli, provides a more salient stimulus that a discrete light, tone or odor stimulus. Second, the unequal associability of contextual versus discrete stimuli may have been more fundamental. As noted by Garcia et al. ([38], p. 795), 'pairing a perceptible cue with an effective reinforcer does not insure effective associative learning; the cue must be appropriate for the consequences that ensue'. For example, it is well known that gustatory stimuli are effective CSs when paired with illness (conditioned taste aversion), but these stimuli are not effective at eliciting conditioned fear when paired with footshock. Conversely, visual, tactile and auditory stimuli (e.g. a distinct environment) are effective at eliciting conditioned fear when paired with footshock, but not a conditioned taste aversion when paired with illness [38]. Thus, it is possible that contextual stimuli are simply more appropriate for conditioning drug responses than more discrete stimuli. For example, because the drug US was relatively longlasting, contextual cues by virtue of their long-lasting and static nature, may have acquired greater associative strength than the discrete stimuli used in the present experiments. Of course, only four different discrete stimuli were tested in the present experiments, and it might be argued that if we tested different stimuli, using different pairing parameters, some combination might prove effective. However, even when a highly salient cue (tone previously paired with footshock) was used to signal drug administration, amphetamine still failed to induce robust sensitization (Experiment 4).

At another level of analysis, the differences between the ability of discrete versus contextual cues to promote sensitization might be due to the fact that these stimuli engage different brain systems $[46,55,64]$. For example, electrolytic lesions of the hippocampus disrupt the acquisition and expression of conditional fear to contextual stimuli, i.e. a distinct environment, but not the acquisition and expression of conditional fear to discrete stimuli, such as tones [51,64]. In contrast, lesions of the amygdala disrupt fear conditioning to either discrete or contextual stimuli [55]. Based on these findings, is has been proposed that the hippocampus plays a particularly important role in conditioning to contextual stimuli, but is not required for conditioning to discrete stimuli. Many researchers believe that the hippocampus is important in contextual learning be- cause it allows for the formation of configural representations [46], although under some conditions rats appear to be able to acquire conditioned fear responding to contextual stimuli through hippocampal-independent mechanisms [55]. Therefore, it is possible that the differences in sensitization as a function of the treatment procedures reported here are related to the fact that conditioning to contextual cues versus discrete cues is mediated by different, albeit overlapping neural systems, one being hippocampal-dependent and one being hippocampal-independent.

Whatever the case, at first glance the present findings appear to be consistent with a Pavlovian excitatory conditioning model of sensitization. Contextual cues that elicited a large CR produced robust sensitization, whereas discrete cues elicited only a small $\mathrm{CR}$ and sensitization was only marginally enhanced. However, closer inspection of the data suggests that a simple excitatory conditioning model cannot account for the group differences in sensitization reported here. For one, the magnitude of the CR was very small in comparison with the magnitude of sensitization. Averaged across experiments, the CR in the NOVEL ${ }^{(a)}$ group was 24.6 rotations and in the $\mathrm{HOME}^{+}$(a) group was 6.1 rotations. The sensitization related increase in rotations in these groups was 193.6 and 70.6 rotations, respectively. That is, the CR was only $\approx 10 \%$ of the sensitized response.

Second, there were interesting differences in the time course of the CR and the time course of the sensitized drug response, especially in the NOVEL ${ }^{(a)}$ group. For example, the peak CR always occurred in the first 15 min interval after presentation of the CS, whereas sensitization-related differences in rotational behavior typically persisted much longer. Furthermore, on the challenge test day the NOVEL ${ }^{\text {(a) }}$ group always showed a biphasic response; that is, an initial peak in activity during the first 5 min interval, a small decline in activity over the next couple of intervals, then a second increase in activity between 20 and $30 \mathrm{~min}$ after drug administration. In contrast, the CR decreased monotonically over the first $15 \mathrm{~min}$ after the saline challenge infusion (compare Panels A and D in Figs. 3, 6 and 9). (As an aside, it is not clear what accounts for the biphasic response in amphetamine-induced rotation following i.v. administration in the NOVEL environment. One speculation is that the first peak coincides with the initial release of free dopamine from the cytoplasmic pool, which is rapidly depleted, and the second peak coincides with repletion of this pool because of liberation of dopamine from the vesicular pool into the cytoplasmic pool. It may also be related to recent observations that 'sensitized' amphetamine-stimulated dopamine release becomes calcium-dependent, unlike 'normal' amphetamine-stimulated dopamine release $[49,68,95])$. 
Third, the hypothesis that the magnitude of sensitization is related to the magnitude of the $\mathrm{CR}$ was tested directly by conducting a correlational analysis. The results indicated that the rate of sensitization was not related to the ability of treatment-related cues to acquire excitatory conditioned stimulus properties (Fig. 11). Of course, it could be argued that the magnitude of the $\mathrm{CR}$ was underestimated in the present experiments because the compound stimulus presented during the saline challenge test did not adequately reproduce the entire CS, because it did not include the interoceptive cues produced by the drug itself [63]. Although, it is quite possible that the saline challenge underestimated the magnitude of the $\mathrm{CR}$, it is also clear that interoceptive cues themselves are not sufficient to promote the development of sensitization. When drug treatments were not signaled by environmental cues $\left(\mathrm{HOME}^{- \text {(a) }}\right.$ group), amphetamine failed to induce sensitization, even after 20 injections. It seems difficult to imagine, therefore, that the inclusion of interoceptive cues to the stimulus complex would make a critical difference.

Finally, in a recent study we manipulated the associability of contextual cues (a distinct test environment) by habituating rats to the drug treatment environment prior to each drug administration [27]. Habituation did not significantly affect the induction of psychomotor sensitization, despite the fact that this manipulation prevented the development of a conditioned response to contextual cues (and markedly attenuated the acute response to amphetamine, see also below). Thus, taken together with the present results, it appears that although the ability of context to facilitate associative learning likely contributes to the long-term behavioral and neurobiological consequences of repeated drug treatments, this contribution appears to be of relatively minor importance for the induction of sensitization. This conclusion is consistent with reports by others indicating that the development of an excitatory CR to treatment-related stimuli is neither necessary nor sufficient for the induction of sensitization [1,5,30,57].

\subsection{Facilitation of non-associative processes by environmental context}

An alternative hypothesis is that drug administration in a distinct and relatively novel test environment promotes robust sensitization through mechanisms unrelated to associative learning. That is, novelty could have modulated the unconditioned stimulus properties of amphetamine to promote sensitization. This possibility is particularly germane considering that the environmental manipulations used here also modulated the acute response to amphetamine. Indeed, we have reported many times that environmental novelty can enhance the acute (unconditioned) response to amphetamine $[5-7,9,19,26]$. However, the effect of en- vironment on the susceptibility sensitization appears to be dissociable from the effect of environment on the acute response to amphetamine (see Section 6.2). This suggests that the differences between groups in sensitization are not merely a function of the effect of environment on the acute response to amphetamine (see Refs. [5,7,78] for a discussion of this point).

Nevertheless, Badiani et al. [9,10] recently described an especially compelling example of how environmental context can modulate the initial neurobiological effects of amphetamine, and in a way that may be relevant to the effects reported here. These authors used in situ hybridization for c-fos mRNA as a marker of neuronal activation, and reported that the pattern of neuronal activation in the cortex, in the caudate, in the shell and core of the nucleus accumbens, and in other subcortical structures was markedly different when an acute i.p. injection of amphetamine was given in a novel test environment, relative to when it was given in the rats' home cage. The ability of novelty to enhance amphetamine-induced c-fos expression in the caudate and/ or nucleus accumbens did not, however, depend on a facilitation of amphetamine-induced release of dopamine in the same brain regions [9]. Furthermore, in a more recent study these researchers used double in situ hybridization to determine whether amphetamine induced c-fos in cells also positive for D1 and/or D2 receptor mRNA [10]. These two cell populations are thought to have different patterns of connectivity, forming the so-called direct and indirect striatonigral pathways [39]. It was found that amphetamine given in the home environment induced a significant increase in c-fos expression in D1 (but not D2) neurons, whereas when given in a novel environment amphetamine induced c-fos expression in both D1 and D2 neurons [10]. This raises the possibility that the ability of contextual stimuli to modulate the susceptibility to sensitization may be related, at least in part, to its ability to modulate the neural circuitry engaged by amphetamine, and to modulate patterns of immediate early gene expression $[9,10]$.

Of course, these studies do not address the potential biopsychological mechanisms by which environmental context modulates immediate early gene expression on the one hand, and the acute response to amphetamine and the induction of psychomotor sensitization, on the other hand. One possibility, which we have discussed previously, is that environmental novelty may modulate both the acute response to amphetamine and susceptibility to sensitization because of some action(s) as a stressor [5-8,78]. Exposure to a novel environment is a potent stimulus for activating the hypothalamic-pituitary-adrenal (HPA)-axis [13]. A single exposure to a novel environment produces an acute increase in corticosterone levels [37,60] and in some situations repeated exposure may produce a progressive increase in plasma 
corticosterone levels, over-and-above the levels produced by acute exposure to novelty [41,42]. Furthermore, it is well established that repeated intermittent exposure to stressors, such a footshock, restraint or tail-pinch, can sensitize rats to the psychomotor stimulant effects of amphetamine [2,3,74]. It is possible, therefore, that drug administration in a relatively novel environment enhanced both the acute response to amphetamine and sensitization because this is also associated with elevated corticosterone levels. Indeed, it has been suggested that behavioral sensitization to amphetamine is critically dependent on corticosteroid receptor activation [72]. However, Badiani et al. [8] have reported that adrenalectomy does not attenuate the effect of environmental novelty on amphetamine sensitization, suggesting that novelty-induced secretion of glucocorticoid hormones do not contribute significantly to this effect. Furthermore, Schmidt et al. [81] have recently reported that changes in HPA-axis functioning, and concomitant changes in $\mathrm{ACTH}$ and corticosterone are neither necessary not sufficient for the expression of amphetamine-induced sensitization. Of course, other stress-related hormones, such as corticotrophin-releasing-hormone $(\mathrm{CRH})$, perhaps acting outside the traditional HPA-axis, could be involved [21]. This possibility remains to be tested.

\section{Conclusions}

In conclusion, the present results show that the ability of amphetamine to induce psychomotor sensitization can be powerfully modulated by environmental stimuli present at the time of drug administration. However, this effect appears to be specific to contextual stimuli. Discrete cues that merely predicted drug administration did not facilitate robust psychomotor sensitization. Although the difference between the ability of contextual versus discrete stimuli to facilitate sensitization may be in part related to differences in their ability to facilitate associative learning processes, it is suggested that the effect of a distinct and relatively novel environment as a stressor may be the critical factor. However, in a recent experiment we found that even after habituating rats to a distinct test environment for 6-8 h prior to each drug administration, robust sensitization was induced. In contrast, this manipulation completely abolished the effect of environment on the acute response to amphetamine [27]. Thus, whatever stress-related mechanism(s) context affects to modulate the induction of sensitization, the temporal dynamics of this effect appear to extend well beyond the immediate biobehavioral consequences of exposure to novelty (i.e. they far outlast the initial 'stress response'). Indeed, these results seem difficult to reconcile with the proposed role of corticosterone secretion in sensitization in light of the transient increase in corticosterone levels typically produced by stressors [37].

Of course, as pointed out by Koolhaas et al. ([52] p. 777), 'stress induces a cascade of neurobiological processes. Each of these processes may have a different time course ranging from milliseconds, in the case of direct transduction processes, to minutes, hours and days when modulatory processes are involved at the level of DNA transcription and peptide synthesis'. Thus, one possible scenario is that exposure to a distinct and relatively novel environment triggers a cascade of cellular processes, presumably including changes in gene expression. This initial 'trigger' may then leave the brain susceptible to drug-induced neuroadaptive processes, perhaps involving growth factors [34,35], even long after the initial triggering event, and thereby facilitate the process of behavioral sensitization. The psychological and neurobiological mechanisms by which this may occur are unknown, but elucidating them will be critical in understanding these kinds of important drug-environment interactions.

\section{Acknowledgements}

Research supported by grant DA 04294 from the National Institute on Drug Abuse to TER.

\section{References}

[1] Anagnostaras SG, Robinson TE. Sensitization to the psychomotor stimulant effects of amphetamine: modulation by associative learning. Behav Neurosci 1996;110:1397-414.

[2] Antelman SM, Chiodo LA. Amphetamine as a stressor. In: Creese I, editor. Stimulants: Neurochemical, Behavioral and Clinical Perspectives. New York: Raven Press, 1983:269-99.

[3] Antelman SM, Eichler AJ, Black CA, Kocan D. Interchangeability of stress and amphetamine in sensitization. Science 1980;207:329-31.

[4] Archer T, Per-Olow S, Lars-Goran N. Contextual control of taste aversion conditioning and extinction. In: Balsam PD, Tomie A, editors. Context and Learning. Hillsdale, NJ: L. Erlbaum, 1985.

[5] Badiani A, Anagnostaras SG, Robinson TE. The development of sensitization to the psychomotor stimulant effects of amphetamine is enhanced in a novel environment. Psychopharmacology 1995; 117:443-52.

[6] Badiani A, Browman KE, Robinson TE. Influence of novel versus home environments on sensitization to the psychomotor stimulant effects of cocaine and amphetamine. Brain Res 1995;674:291-8.

[7] Badiani A, Camp DM, Robinson TE. Enduring enhancement of amphetamine sensitization by drug-associated environmental stimuli. J Pharmacol Exp Ther 1997;282:787-94.

[8] Badiani A, Morano MI, Akil H, Robinson TE. Circulating adrenal hormones are not necessary for the development of sensitization to the psychomotor activating effects of amphetamine. Brain Res 1995;673:13-24.

[9] Badiani A, Oates MM, Day HEW, Watson SJ, Akil H, Robinson TE. Amphetamine-induced behavior, dopamine re- 
lease, and c-fos mRNA expression: modulation by environmental novelty. J Neurosci 1998;18:10579-93.

[10] Badiani A, Oates MM, Day HEW, Watson SJ, Akil H, Robinson TE. Environmental modulation of amphetamine-induced c-fos expression in D1 versus D2 striatal neurons. Behav Brain Res 1999;103:203-9.

[11] Badiani A, Oates MM, Robinson TE. Modulation of morphine sensitization in the rat by contextual stimuli. Psychopharmacology 2000 (in press).

[12] Balsam PD, Tomie A. Context and Learning. Wahwah, NJ: Erlbaum, 1985.

[13] Bardo MT, Donohew RL, Harrington NG. Psychobiology of novelty seeking and drug seeking behavior. Behav Brain Res 1996;77:23-43.

[14] Barr GA, Sharpless NS, Cooper S, Schiff SR, Paredes W, Bridger WH. Classical conditioning, decay and extinction of cocaine-induced hyperactivity and stereotype. Life Sci 1983;33:1341-51.

[15] Beck CHM, Chow HL, Cooper SJ. Initial environment influences amphetamine-induced stereotype: subsequently environment change has little effect. Behav Neural Biol 1986;46:383-97.

[16] Breese GR, Traylor TD. Depletion of brain noradrenaline and dopamine by 6-hydroxydopamine. Br J Pharmacol 1971;42:8899.

[17] Bridger WH, Schiff SR, Cooper SS, Paredes W, Barr GA. Classical conditioning of cocaine's stimulatory effects. Psychopharmacol Bull 1982;18:210-4.

[18] Browman KE, Badiani A, Robinson TE. The influence of environment on the induction of sensitization to the psychomotor activating effects of intravenous cocaine in rats is dose-dependent. Psychopharmacology 1998;137:90-8.

[19] Browman KE, Badiani A, Robinson TE. Modulatory effect of environmental stimuli on the susceptibility to amphetamine sensitization: a dose-effect study in rats. J Pharmacol Exp Ther 1998;287:1007-14.

[20] Brown ZW, Amit Z, Weeks JR. Simple flow-through swivel for infusions into unrestrained animals. Pharmacol Biochem Behav 1976;5:363-5.

[21] Cador M, Cole BJ, Koob GF, Stinus L, Le Moal M. Central administration of corticotropin releasing factor induces longterm sensitization to D-amphetamine. Brain Res 1993;606:181-6.

[22] Carey RJ. Conditioned rotational behavior in rats with unilateral 6-hydroxydopamine lesions of the substantia nigra. Brain Res 1986;365:379-82.

[23] Casas M, Guix T, Prat G, Ferre S, Cadafalch J, Jane F. Conditioning of rotational behavior after the administration of a single dose of apomorphine in rats with unilateral denervation of the dopaminergic nigrostriatal pathway: relevance to drug addiction. Pharmacol Biochem Behav 1988;31:605-9.

[24] Cho AK, Melega WP, Kuczenski R, Segal DS, Schmitz DA. Caudate-putamen dopamine and stereotypy response profiles after intravenous and subcutaneous amphetamine. Synapse 1999;31:125-33.

[25] Crombag HC, Mueller H, Browman KE, Badiani A, Robinson TE. A comparison of two behavioral measures of psychomotor activation following intravenous amphetamine or cocaine: doseand sensitization-dependent changes. Behav Pharmacol 1999;10:205-13.

[26] Crombag HS, Badiani A, Robinson TE. Signalled versus unsignalled intravenous amphetamine: large differences in the acute psychomotor response and sensitization. Brain Res 1996;722:227-31.

[27] Crombag HS, Dineen S, Badiani A, Robinson TE. Novelty induced enhancement of the acute psychomotor effects of amphetamine and sensitization: role of habituation. Soc Neurosci Abst 1999;25:309.
[28] Dahl CB, Gotestam KG. Tissue level related stereotyped behaviour after intravenous amphetamine in rats. Acta Pharmacol Toxicol (Copenhagen) 1986;58:169-74.

[29] Damianopoulos EN, Carey RJ. Conditioning, habituation and behavioral organization factors in chronic cocaine effects. Behav Brain Res 1992;49:149-57.

[30] Drew KL, Glick SD. Characterization of the associative nature of sensitization to amphetamine-induced circling behavior and the environment dependent placebo-like response. Psychopharmacology 1988;95:482-7.

[31] Echols SD. Circling of mice bearing unilateral striatal lesions: development of increased response to D-amphetamine. Life Sci 1977;21:563-8.

[32] Ellinwood EH, Kilbey MM. Amphetamine stereotypy: the influence of environmental factors and prepotent behavioral patterns on its topography and development. Biol Psychiatry 1975;10:316.

[33] Ferger B, Kuschinsky K. A comparison of different sensory stimuli in producing conditioned apomorphine effects. Behav Pharmacol 1995;6:40-5.

[34] Flores C, Rodaros D, Stewart J. Long-lasting induction of astrocytic basic fibroblast growth factor by repeated injections of amphetamine: blockade by concurrent treatment with a glutamate antagonist. J Neurosci 1998;18:9547-55.

[35] Flores C, Samaha A-N, Stewart J. Requirement of endogenous basic fibroblast growth factor for sensitization to amphetamine. J Neurosci 2000;C55:1-5.

[36] Fraioli S, Crombag HS, Badiani A, Robinson TE. Susceptibility to amphetamine-induced locomotor sensitization is modulated by environmental stimuli. Neuropsychopharmacology 1999;20:533-41.

[37] Friedman SB, Ader R. Adrenocortical response to novelty and noxious stimulation. Neuroendocrinology 1967;2:209-12.

[38] Garcia J, McGowan BK, Ervin FR, Koelling RA. Cues: their relative effectiveness as a function of the reinforcer. Science 1968;160:794-5.

[39] Gerfen CR, Engber TM, Mahan LC, Susel Z, Chase TN, Monsma FJJ, Sibley DR. D1 and D2 dopamine receptor-regulated gene expression of striatonigral and striatopallidal neurons. Science 1990;250:1429-32.

[40] Hefti F, Melamed E, Wurtman RJ. Partial lesions of the dopaminergic nigrostriatal system in rat brain: biochemical characterization. Brain Res 1980;195:123-37.

[41] Hennessy MB. Sensitization of the plasma corticosterone response to novel environments. Physiol Behav 1991;50:1175-9.

[42] Hennessy MB, Levine S. Effects of various habituation procedures on pituitary-adrenal responsiveness in the mouse. Physiol Behav 1977;18:799-802.

[43] Hinson RE, Poulos CX. Sensitization to the behavioral effects of cocaine: modification by Pavlovian conditioning. Pharmacol Biochem Behav 1981;15:559-62.

[44] Hirabayashi M, Alam MR. Enhancing effect of methamphetamine on ambulatory activity produced by repeated administration in mice. Pharmacol Biochem Behav 1981;15:925-32.

[45] Hiroi N, White NM. Conditioned stereotypy: behavioral specification of the UCS and pharmacological investigation of the neural change. Pharmacol Biochem Behav 1989;32:249-58.

[46] Holland PC, Bouton ME. Hippocampus and context in classical conditioning. Curr Opin Neurobiol 1999;9:195-202.

[47] Horger BA, Shelton K, Schenk S. Preexposure sensitizes rats to the rewarding effects of cocaine. Pharm Biochem Behav 1990;37:707-11.

[48] Kamin LJ. Temporal and intensity characteristics of the conditioned stimulus. In: Prokasy WF, editor. Classical Conditioning. New York: Meridith, 1965:118-47.

[49] Kantor L, Hewlett GH, Gnegy ME. Enhanced amphetamineand $\mathrm{K}^{+}$-mediated dopamine release in rat striatum after re- 
peated amphetamine: differential requirements for $\mathrm{Ca}^{2+}$ - and calmodulin-dependent phosphorylation and synaptic vesicles. J Neurosci 1999;19:3801-8.

[50] Katner SN, Magalong JG, Weiss F. Reinstatement of alcoholseeking behavior by drug-associated discriminative stimuli after prolonged extinction in the rat. Neuropsychopharmacology 1999;20:471-9.

[51] Kim JJ, Fanselow MS. Modality-specific retrograde amnesia of fear. Science 1992;256:675-7.

[52] Koolhaas JM, Meerlo P, De Boer SF, Strubbe JH, Bohus B. The temporal dynamics of the stress response. Neurosci Biobehav Rev 1997;21:775-82.

[53] Lett BT. Repeated exposures intensify rather than diminish the rewarding effects of amphetamine, morphine, and cocaine. Psychopharmacology (Berlin) 1989;98:357-62.

[54] Magos L. Persistence of the effect of amphetamine on stereotyped activity on rats. Eur J Pharmacol 1969;6:200-1.

[55] Maren S, Aharonov G, Fanselow MS. Neurotoxic lesions of the dorsal hippocampus and Pavlovian fear conditioning in rats. Behav Brain Res 1997;88:261-74.

[56] Marshall JF, Ungerstedt U. Supersensitivity to apomorphine following destruction of the ascending dopamine neurons: quantification using the rotational model. Eur $\mathbf{J}$ Pharmacol 1977;41:361-7.

[57] Martin-Iverson M, Fawcett S. Pavlovian conditioning of psychomotor stimulant-induced behaviors: has convenience led us astray? Behav Pharmacol 1996;7:24-41.

[58] Mazurski EJ, Beninger RJ. Environment-specific conditioning and sensitization with $(+)$-amphetamine. Pharmacol Biochem Behav 1987;27:61-5.

[59] McFarlane DK, Martonyi BJ, Robinson TE. An inexpensive automated system for the measurement of rotational behavior in small animals. Behav Res Meth Inst Comp 1992; 24:414-9.

[60] Misslin R, Herzog F, Koch B, Ropartz P. Effects of isolation, handling and novelty on the pituitary-adrenal response in the mouse. Psychoneuroendocrinology 1982;7:217-21.

[61] Panlilio LV, Schindler CW. Conditioned locomotor activating and reinforcing effects of discrete stimuli paired with intraperitoneal cocaine. Behav Pharmacol 1997;8:691-8.

[62] Pavlov IP. Conditioned Reflexes (CV Anrep Trans). London: Oxford University Press, 1927.

[63] Pert A, Post R, Weiss SR. Conditioning as a critical determinant of sensitization induced by psychomotor stimulants. NIDA Res Monogr 1990;97:208-41.

[64] Phillips RG, LeDoux JE. Differential contribution of amygdala and hippocampus to cued and contextual fear conditioning. Behav Neurosci 1992;106:274-85.

[65] Piazza PV, Deminière JM, Le Moal M, Simon H. Factors that predict individual vulnerability to amphetamine self-administration. Science 1989;245:1511-3.

[66] Pickens R, Dougherty JA. Conditioning of the activity effects of drugs. In: Thompson T, Schuster C, editors. Stimulus Properties of Drugs. New York: Appleton-Century-Croft, 1971:3950.

[67] Pickens RW, Crowder WF. Effects of CS-US interval on conditioning of drug response, with assessment of speed of conditioning. Psychopharmacology 1967;11:88-94.

[68] Pierce RC, Kalivas PW. Repeated cocaine modifies the mechanism by which amphetamine releases dopamine. J Neurosci 1997;17:3254-61.

[69] Post RM, Weiss SR, Fontana D, Pert A. Conditioned sensitization to the psychomotor stimulant cocaine. In: Kalivas PW, Samson HH, editors. Annals of the New York Academy of Sciences: The Neurobiology of Drug and Alcohol Addiction. New York: The New York Academy of Sciences, 1992:38699.
[70] Post RM, Weiss SR, Pert A. The role of context and conditioning in behavioral sensitization to cocaine. Psychopharmacol Bull 1987;23:425-9.

[71] Rescorla RA, Wagner AR. A theory of Pavlovian conditioning: variations in the effectiveness of reinforcement and nonreinforcement. In: Black AH, Prokasy WF, editors. Classical Conditioning II: Current Research and Theory. New York: Appleton-Century-Crofts, 1972:64-99.

[72] Rivet JM, Stinus L, LeMoal M, Mormede P. Behavioral sensitization to amphetamine is dependent on corticosteroid receptor activation. Brain Res 1989;498:149-53.

[73] Robinson TE. Behavioral sensitization: characterization of enduring changes in rotational behavior produced by intermittent injections of amphetamine in male and female rats. Psychopharmacology 1984;84:466-75.

[74] Robinson TE. Stimulant drugs and stress: factors influencing individual differences in the susceptibility to sensitization. In: Kalivas PW, Barnes C, editors. Sensitization of the Nervous System. Caldwell, NJ: Telford Press, 1988:145-73.

[75] Robinson TE. Persistent sensitizing effects of drugs on brain dopamine systems and behavior: implications for addiction and relapse. In: Korenman SG, Barchas JD, editors. Biological Basis of Substance Abuse. New York: Oxford University Press, 1993:373-402.

[76] Robinson TE, Becker JB. Enduring changes in brain and behavior produced by chronic amphetamine administration: a review and evaluation of animal models of amphetamine psychosis. Brain Res Rev 1986;11:157-98.

[77] Robinson TE, Berridge KC. The neural basis of drug craving: An incentive-sensitization theory of addiction. Brain Res Rev 1993;18:247-91.

[78] Robinson TE, Browman KE, Crombag HS, Badiani A. Modulation of the induction or expression of psychostimulant sensitization by the circumstances surrounding drug administration. Neurosci Biobehav Rev 1998;22:347-54.

[79] Schallert T, De Ryck M, Teitelbaum P. Atropine stereotypy as a behavioral trap: a movement subsystem and electroencephalographic analysis. J Comp Physiol Psychol 1980;94:1-24.

[80] Schiff SR. Conditioned dopaminergic activity. Biol Psychiatry 1982;17:135-54.

[81] Schmidt ED, Tilders FJ, Binnekade R, Schoffelmeer AN, De Vries TJ. Stressor- or drug-induced sensitization of the corticosterone response is not critically involved in the long-term expression of behavioural sensitization to amphetamine. Neuroscience 1999;92:343-52.

[82] Segal DS. Behavioral and neurochemical correlates of repeated D-amphetamine administration. Adv Biochem Psychopharmacol 1975;13:247-62.

[83] Segal DS, Kuczenski R. Behavioral pharmacology of amphetamine. In: Cho AK, Segal DS, editors. Amphetamine and Its Analogs: Psychopharmacology, Toxicology and Abuse. San Diego: Academic Press, 1994:115-50.

[84] Segal DS, Schuckit MA. Animal models of stimulant-induced psychosis. In: Creese I, editor. Stimulants: Neurochemical, Behavioral and Clinical Perspectives. New York: Raven Press, 1983:131-67.

[85] Siegel S. Drug anticipation and drug tolerance. In: Lader M, editor. The Psychopharmacology of Addiction. New York: Oxford University Press, 1988:73-97.

[86] Slawecki CJ, Samson HH, Chappell A. Intranucleus accumbens amphetamine infusions enhance responding maintained by a stimulus complex paired with oral ethanol self-administration. Pharmacol Biochem Behav 1997;58:1065-73.

[87] Stewart J, Badiani A. Tolerance and sensitization to the behavioral effects of drugs. Behav Pharmacol 1993;4:289-312.

[88] Stewart J, Vezina P. Conditioning and behavioral sensitization. In: Kalivas PW, Barnes CD, editors. Sensitization in the Nervous System. Caldwell, NJ: Telford Press, 1988:207-24. 
[89] Sullivan R, Dogaru C, Szechtman H. Constriction of environmental space and the behavioral response to the dopamine agonist quinpirole. Pharmacol Biochem Behav 1992;43:1217.

[90] Terelli E, Terry P. Amphetamine-induced conditioned activity and sensitization: the role of habituation to the test context and the involvement of Pavlovian processes. Behav Pharmacol 1999;9:409-19.

[91] Tilson HA, Rech RA. Conditioned drug effects and absence of tolerance to D-amphetamine induced motor activity. Pharmacol Biochem Behav 1973;1:149-53.

[92] Ungerstedt U, Arbuthnott GW. Quantitative recording of rotational behavior in rats after 6-hydroxy-dopamine lesions of the nigrostriatal dopamine system. Brain Res 1970;24:485-93.
[93] Valone JM, Randall CK, Kraemer PJ, Bardo MT. Olfactory cues and morphine-induced conditioned analgesia in rats. Pharmacol Biochem Behav 1998;60:115-8.

[94] Vezina P, Stewart J. Conditioning and place-specific sensitization of increases in activity induced by morphine in the VTA. Pharmacol Biochem Behav 1984;20:925-34.

[95] Warburton EC, Mitchell SN, Joseph MH. Calcium dependence of sensitized dopamine release in the rat nucleus accumbens following amphetamine challenge: implications for the disruption of latent inhibition. Behav Pharmacol 1996;7:119-29.

[96] Weeks JR. Long-term intravenous infusions. In: Meyers RD, editor. Methods in Psychobiology. London: Academic Press, 1972:155-68. 